\title{
Frank Büttner
}

\section{»Argumentatio « in Bildern der Reformationszeit}

Ein Beitrag zur Bestimmung argumentativer Strukturen in der Bildkunst

In dem von der Antike bis in die Neuzeit tradierten System der Rhetorik war die argumentatio der zentrale Teil einer Rede. Sie folgte auf die narratio, die Darlegung des Sachverhaltes, und hatte das Ziel, die Beweise für die eigene Sache schlüssig und glaubwürdig auszubreiten, um die Zuhörer $\mathrm{zu}$ überzeugen ${ }^{\mathrm{I}}$. In den kunstgeschichtlichen Untersuchungen, die dem Einfluß der Rhetorik auf die bildende Kunst nachspürten, standen die Fragen nach dem System der Stillagen und nach den Wirkungsfunktionen docere, delectare und move$r e$ im Vordergrund des Interesses ${ }^{2}$. Die Frage nach der argumentatio des Bildes wurde jedoch kaum berührt. Zu erwarten gewesen wäre auch und vielleicht sogar noch eher, daß die Bildargumentation aus einer allgemeineren Perspektive unseres $\mathrm{Fa}$ ches in den Blick gekommen wäre, nämlich aus der Perspektive der in jüngster Zeit lebhaft betriebenen Erforschung der Bilderzählung ${ }^{3}$. Die Frage, ob es neben den unter verschiedenen Aspekten untersuchten Erzählstrukturen auch argumentative Strukturen gibt und wie diese zu definieren wären, wurde aber bislang, soweit ich sehe, nicht gestellt. Der Begriff der Argumentation von Bildern ist gleichwohl nicht unbekannt. Er taucht

${ }^{I}$ G. Uding, B. Steinbrink, Grundriß der Rhetorik. Geschichte, Technik, Methode, Stuttgart 1986, 245ff.; Historisches Wörterbuch der Rhetorik, hrsg. von G. Ueding, Bd. r, Tübingen 1992, Sp. 88gff. (M. Kienpointer, $»$ Argument $\%$ W. E. Veit, »Argumentatio«; E. Eggs, $\gg$ Argumentation $\ll$ ).

${ }^{2}$ Vgl. R. W. Lee, Ut pictura poesis. The humanistic theory of Painting, New York 1967; A. Ellenius, De arte pingendi. Latin Art Literature in Sweden and its Iternational Background, Uppsala 1960; U. Mildner-Flesch, Das Decorum. Herkunft, Wesen und Wirkung des Sujetstils am Beispiel Nicolas Poussins, Köln 1983; K. Patz, Zum Begriff der $>$ Historia in L. B. Albertis $>$ De Picturar, in: Zeitschrift für Kunstgeschichte, Bd. 49, 1986, 269ff.; F. Büttner, Rhetorik und barocke Deckenmalerei. Überlegungen am Beispiel der Fresken Johann Zicks in Bruchsal, in: Zeitschrift des Deutschen Vereins für Kunstwissenschaft, Bd. 43, 1989, $49 \mathrm{ff.}$ beispielsweise im Untertitel des von Belting und Blume herausgegebenen Sammelbandes über die $>$ Malerei und Stadtkultur in der Dantezeit< auf ${ }^{4}$. In den Texten freilich wird der Begriff dann in recht unterschiedlicher Bedeutung verwendet. Eine systematische Untersuchung des Begriffes findet man weder dort noch anderwärts.

Ich möchte hier etwas von dem Versäumten nachholen und einige Aspekte der Bildargumentation betrachten, wobei ich mich in erster Linie auf Bildbeispiele aus der Frühzeit des Protestantismus beziehen werde, insbesondere auf Werke von Lukas Cranach und seiner Werkstatt. Dabei steht im ersten Teil meiner Ausführungen eine Gruppe von Werken im Mittelpunkt, die erst kürzlich von Friedrich Ohly in seiner Arbeit > Gesetz und Evangeliume ausführlich behandelt worden ist ${ }^{5}$. Wenn ich hier noch einmal auf diese Werkgruppe zurückgreife, so in erster Linie deswegen, weil sie sich besonders gut eignet, meine Thesen zur argumentatio des Bildes zu illustrieren, zum anderen, weil die Ausführungen Ohlys in wichtigen Punkten zu ergänzen oder auch zu korrigieren sind.

Um thesenhaft den Unterschied von narrativer und argumentativer Darstellung zu verdeutlichen,

${ }^{3}$ Literaturübersichten zu diesem Thema bei W. Kemp (Hrsg.), Der Text des Bildes. Möglichkeiten und Mittel eigenständiger Bilderzählung (Literatur und andere Künste, Bd. 4), München 1989, II6ff.; W. Harms, Text und Bild, Bild und Text (Germanistische Symposien, Berichtsbände, Bd. II), Stuttgart 1990, $475 \mathrm{ff}$.

${ }^{4} \mathrm{H}$. Belting und D. Blume (Hrsg.), Malerei und Stadtkultur in der Dantezeit. Die Argumentation der Bilder, München 1989. Mit den hier vorgelegten Überlegungen berühren sich besonders eng die in diesem Band iziff. publizierten Ausführungen von R. Colella über $»$ Die Erlösungsallegorie von Ambrogio Lorenzettix (vgl. dazu unten Anm. 8r).

sF. Ohly, Gesetz und Evangelium. Zur Typologie bei Luther und Cranach (Schriftenreihe der Westrälischen Wilhelms-Universität Münster, Bd. I), Münster 1985. 
möchte ich mit der Gegenüberstellung von zwei Cranachbildern beginnen, die beide das Thema der Kreuzigung behandeln. Daß es sich in dem einem Fall um das wohl früheste bekannte Werk, im anderen um ein spätes Werk handelt, das gelegentlich als Cranachs »Epitaph « bezeichnet wurde, ist zufällig, aber vielleicht doch nicht ganz zufällig.

Die um 1500 in Wien gemalte $>$ Kreuzigung $(A b b . r)^{6}$, heute im Kunsthistorischen Museum, entstand in der damals noch gar nicht so alten Tradition narrativer Andachtsbilder?. Cranach bemühte sich, die Szene so lebendig wie möglich zu vergegenwärtigen. Aktion und Ausdruck der einzelnen Figur, die Figurenbeziehungen, der Ort der Figuren im Landschaftsraum wie auf der Bildfläche konstituieren einen Bildtext ${ }^{8}$, der vom $\mathrm{Be}-$ trachter als Handlung erfahren wird, oder genauer: als Moment einer Handlung, deren Verlauf von dem, was war, zu dem, was sein wird, aus den in den Bildelementen gegebenen Andeutungen von Bewegung ablesbar ist. Daß der Betrachter die dargestellte Handlung um so besser verstehen wird, je mehr Kenntnisse von der Geschichte er in das Bild hineinprojizieren kann, braucht hier sicher nicht eigens betont zu werden.

Die Mitteltafel des Weimarer Altars (Abb. 2) ist demgegenüber ein aufschlußreiches Beispiel argumentativer Darstellung. Die alte Frage nach dem Anteil des älteren Cranach an diesem Altar, der erst I555, also zwei Jahre nach seinem Tode aufgestellt wurde und somit weitgehend oder vielleicht sogar ganz als Werk des jüngeren Cranach gelten muß, dürfen wir hier, wo es um Probleme der Darstellung geht, beiseite lassen ${ }^{9}$. Der Betrachter kann aus der Zusammenstellung der Figuren auf diesem Bild keinen szenischen Zusammenhang,

${ }^{6} \mathrm{M}$. J. Friedländer und J. Rosenberg, Die Gemälde von. Lucas Cranach, Stuttgart 1989, 66, Nr. I.

${ }^{7} \mathrm{Zu}$ dieser Tradition vgl. R. Suckale, Süddeutsche szenische Andachtsbilder um 1420-1450. Erzählung im Spannungsfeld zwischen Kultur- und Andachtsbild, in: Harms (Hrsg.) (Anm. 3), Isff.

${ }^{8}$ Zur kunstgeschichtlichen Verwendung des Textbegriffes vgl. G. Kauffmann, Zum Verhältnis von Text und Bild in der Renaissance (Rheinisch-Westfälische Aka- keine Handlung rekonstruieren. Die Figuren, die dem Kruzifix beigegeben wurden, haben mit der Kreuzigung als historischem Geschehen nichts zu tun. Allenfalls die Darstellung des Tod und Teufel besiegenden Christus links könnte als Wiedergabe eines auf die Hauptszene folgenden Handlungsmomentes verstanden werden, jedoch nicht in der hier gegebenen Form. Völlig aus dem Rahmen der Historie fallen das Lamm und die Gestalt Cranachs zwischen Johannes dem Täufer und Luther. Auch das unmittelbare Nebeneinander der Szene mit der Ehernen Schlange Mosis und der Verkündigung an die Hirten kann der Betrachter nicht in eine kohärente Erzählung auflösen. Genauso wenig läßt die Darstellung des nackten Menschen, der von Tod und Teufel verfolgt wird, während Moses und die Propheten hinter ihm auf die Gesetzestafeln zeigen, eine erzählerische Verbindung mit den anderen Bildmotiven erkennen. Während der Bildtext in der frühen Kreuzigungsdarstellung einheitlich und kohärent ist, ist er hier durch Diskontinuitäten gekennzeichnet.

Um die so umschriebene Eigenart des Weimarer Altares zu kennzeichnen, bediente sich Ohly des Begriffes des »Simultanbildes . Ich halte diesen Begriff in diesem Zusammenhang für schwierig, weil seine Konnotationen von den Besonderheiten der Bildstruktur eher ablenken. Das möchte ich mit ein paar begriffsgeschichtlichen Bemerkungen erläutern. Der Begriff $»$ Simultanbild wird heute üblicherweise als Darstellung von zeitlich oder räumlich auseinanderliegenden $\mathrm{Er}$ eignissen in einem Bild $\ll$ definiert ${ }^{\mathrm{ro}}$. Wenn man hier von der konstitutiven Bedeutung des Konzeptes der Simultaneität für die Malerei des Kubismus und des Futurismus einmal absieht, so ist für die Kunstwissenschaft Dagobert Frey als einer der

demie der Wissenschaften, Vorträge G. 249), Opladen 1980, bes. S. I6ff.

9 Friedländer/Rosenberg (Anm. 6), 158, Nr. 434; O. Thulin, Cranach-Altäre der Reformation, Berlin 1955, 54 ff.; W. Schade, Die Malerfamilie Cranach, Dresden r974, 92 hält den Altar für ein Werk L. Cranachs d. J.

${ }^{10}$ Deutsches Fremdwörterbuch, beg. von $\mathrm{H}$. Schulz, weitergef. vom Institut für deutsche Sprache, Bd. 4, Berlin 1978, S. I9of. 


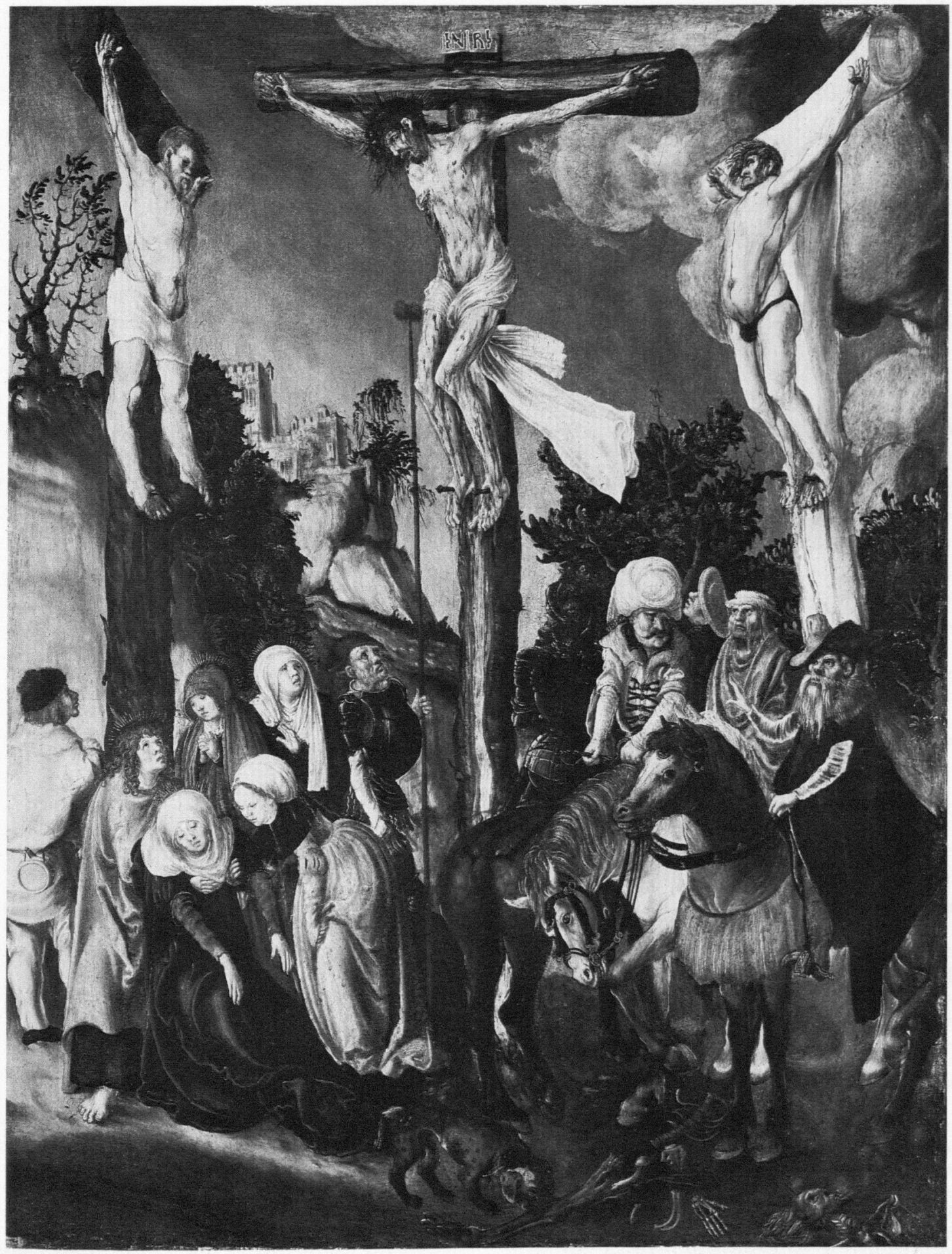

I. Lukas Cranach d. Ä., Kreuzigung Christi, Wien, Kunsthistorisches Museum 


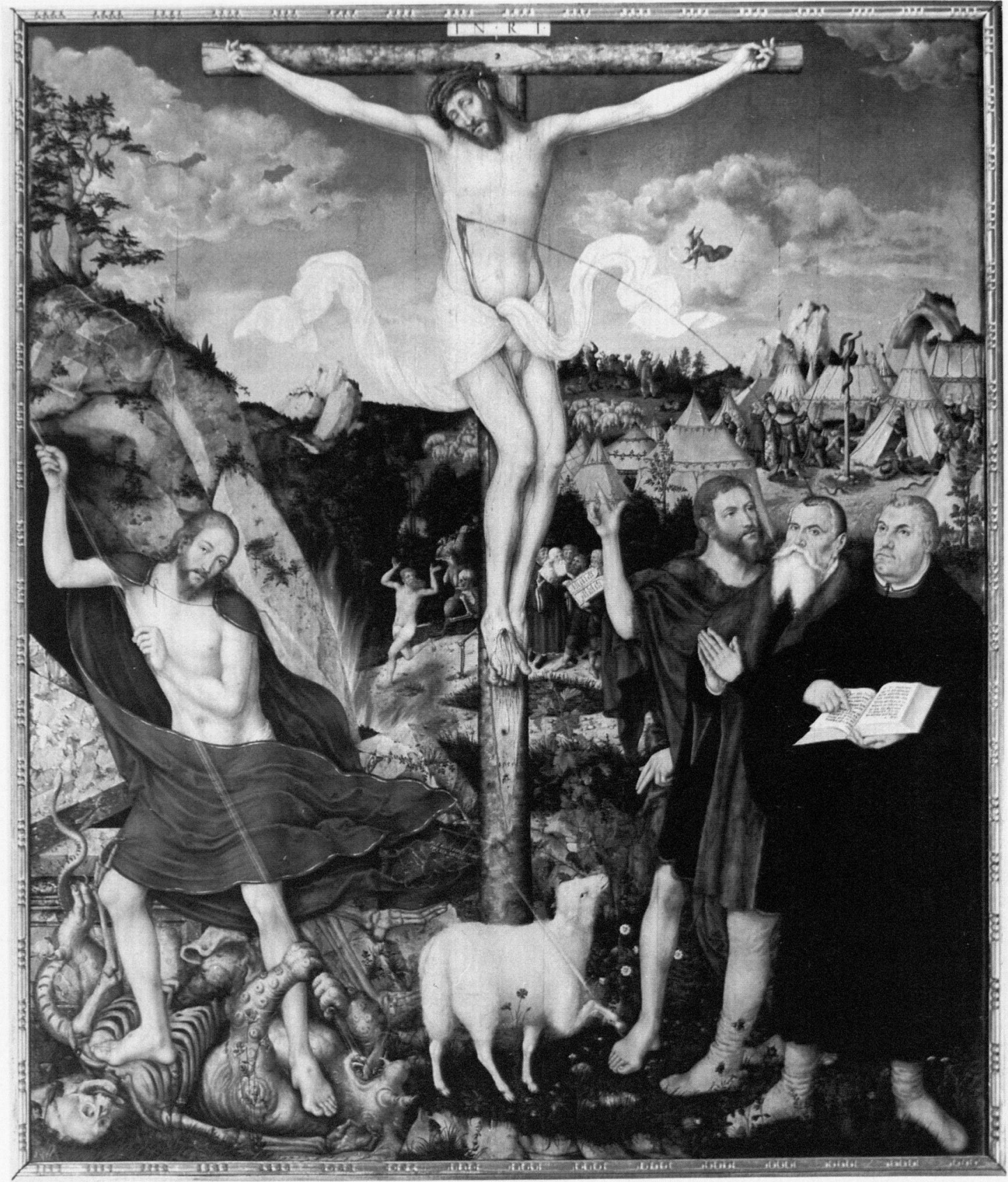

2. Lukas Cranach d. Ä., Kreuzigung Christi, Mittelbild des Weimarer Altars, Weimar, Stadtkirche St. Peter und Paul

ersten anzuführen, der den Begriff der Simultaneität verwandte. Er wollte damit die besondere Betrachtungsweise der Renaissance charakterisieren, die, so seine Worte, »das Bild in allen seinen Teilen als Ganzes gleichsam mit einem Blick erfaßt« hat und sich darin grundsätzlich von der Gotik unter- 
schied, deren Betrachtungsweise sukzessives Ab-

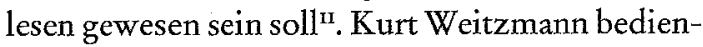
te sich 1947 des Begriffs »simultaneous method «, um eine Darstellungsweise zu bezeichnen, bei der "within the limits of a single scene several actions take place at the same time ${ }^{\mathrm{I}}{ }^{\mathrm{I}}$. Ehrenfried Kluckert hat 1974 eine Dissertation über die >Erzählform des mittelalterlichen Simultanbildes verfaßt, in der er diese Bildform wie Weitzmann definiert, ohne explizit auf ihn einzugehen ${ }^{\mathrm{r} 3}$. Konstitutiv für das Simultanbild sind für Kluckert der einheitliche Bildraum und die Erzählstruktur, von ihm näher bestimmt als »formale Konstruktion des Handlungsablaufes ${ }^{14}$. Als beispielhaft führt Kluckert Memlings Darstellung der Passion in Turin an ${ }^{\mathrm{TS}}$. Das Bild zeigt in einer Architekturlandschaften die Passionsszenen, die vom Betrachter als narrative Sequenz rezipiert werden. Das »zusammen« der Darstellung bedeutet in derartigen Darstellungen keineswegs notwendigerwiese ein "zugleich «. Die Bezeichnung des Weimarer Altares als $\gg$ Simultanbild « ist also problematisch, weil dieser Terminus einen narrativen Zusammenhang impliziert, der hier offensichtlich nicht gegeben ist und weil er zugleich die Vorstellung von Gleichzeitigkeit suggeriert, die, auch wenn sie als ideelle Gleichzeitigkeit verstanden wird, geeignet ist, die Fragen zu verschleiern, die durch die hier gegebene Zusammenstellung der Bildmotive aufgeworfen werden. Ich meine, daß man mit dem bislang in unsèrem Fach noch ungebräuchlichen Begriff der argumentativen Struktur der Eigenart des Bildes besser gerecht werden kann.

II D. Frey, Gotik und Renaissance als Grundlagen der modernen Weltanschauung, Augsburg 1929, 38.

${ }^{12} \mathrm{~K}$. Weitzmann, Illustrations in Roll and Codex. A Study of the Origin of Text Illustration, 2. Aufl., Princeton 1970, I4; er möchte mit seinem Terminus den von F. Wickhoff geprägten Begriff des »komplettierenden Erzählstils" ersetzen; vgl. F. Wickhoff und W. von Hartel, Die Wiener Genesis, Wien 1895.

${ }^{\text {r3 }}$ E. Kluckert, Die Erzählformen des mittelalterlichen Simultanbildes, Phil. Diss. Tübingen 974: Im Simultanbild werden wzeitlich aufeinanderfolgende Szenen in einen einheitlichen Bildraum gestellt* (ebd. r). Klukkert schreibt 2: "Simultan< wird diese Bildform deswegen genannt, weil der Betrachter alles, was im Bilde nacheinander zu geschehen scheint, sauf ein Mak er-
Für den Betrachter, der in den Zeiten der unbestrittenen Vorherrschaft mimetischer Kunst von dem Axiom ausgehen konnte, daß ein Bild ein in sich sinnvolles Ganzes ist, wirkten die Motivkollisionen und Brüche, wie er sie im Weimarer Altar vorfindet, als Signal. Er mußte sich dadurch aufgefordert fühlen, die evidenten Lücken im Bildtext zu schließen. Da dies auf der Ebene des Narrativen - für den mit dem Konzept mimetischer Kunst aufgewachsenen Betrachter die Normalebene nicht möglich ist, wird er die Verständnisebene wechseln und prüfen, ob auf einer abstrakteren Ebene Kontinuität des Bildsinnes herzustellen ist. Die wichtigste der hier in Frage kommenden abstrakten übergeordneten Verständnisebenen, auf der sich auch der weniger gebildete Betrachter ohne Schwierigkeiten zurechtfinden konnte, war die Argumentation, in der ja einzelne Feststellungen wie auch komplexere Aussagen und umfangreichere Erzählungen, die dann als Exempel fungieren, so zusammengefügt werden, daß sie zu einem bestimmten Schluß führen. Auf dieser übergeordneten Verständnisebene werden die einzelnen Bildmotive zu Gliedern einer Argumentationskette. Die Bildaussage wird als in sich schlüssige Argumentation aufgefaßt und verstanden.

Diesen Vorgang der Sinnkonstitution als Nachvollziehen der Bildargumentation möchte ich näher erläutern, allerdings zunächst nicht am Weimarer Altar, sondern an der unmittelbaren ikonographischen Quelle dieses Werkes, einer Bilderfindung des älteren Cranach, die Darstellung von ,Gesetz und Evangelium ${ }^{16}$. Die große Zahl der

fährt«. Diese Erläuterung verdreht den Tatbestand, denn natürlich bietet das Bild nur den Schein der Gleichzeitigkeit, die bei genauerer Bildlektüre aber in ein Nacheinander aufgelöst wird.

${ }^{14}$ Kluckert (Anm. I2), , 16 f.

${ }^{15} \mathrm{C}$. Aru und E. de Gerardon, La Galerie Sabauda de Turin (Les Primitifs Flamands), Antwerpen 1952, 14ff.

${ }^{16}$ Thulin (Anm. 8), 126ff.; D. Köpplin und T. Falk, Lukas Cranach. Gemälde, Zeichnungen, Druckgraphik, Katalog der Ausstellung im Kunstmuseum Basel 1974, Bd. 2, sosff.; C. D. Andersson, Religiöse Bilder Cranachs im Dienste der Reformation, in: L. W. Spitz (Hrsg.), Humanismus und Reformation als religiöse Kräfte in der deutschen Geschichte (Veröffentlichungen der Historischen Kommission, Bd. 51), Berlin 198I, 


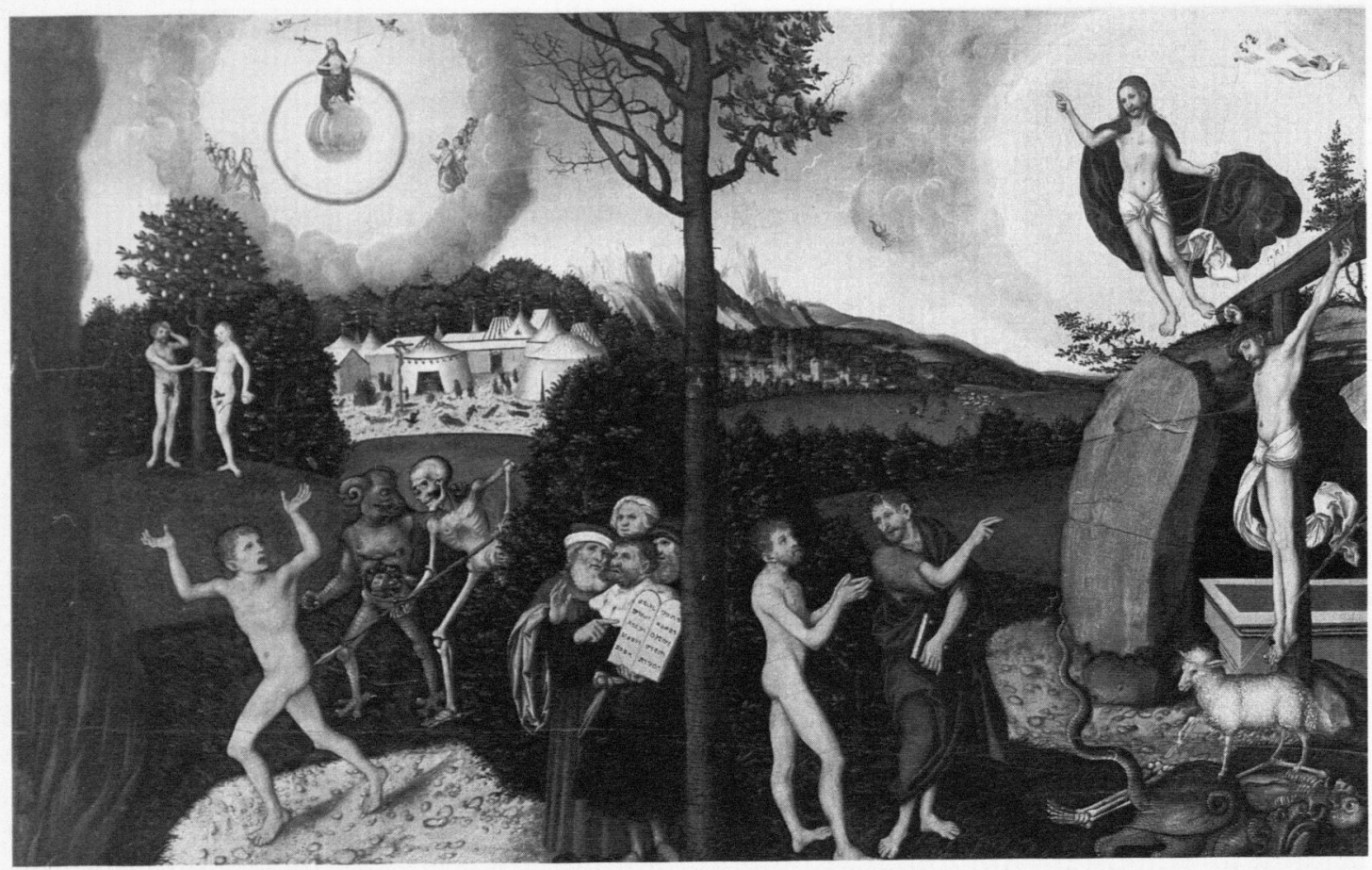

3. Lukas Cranach d. Ä., Gesetz und Evangelium, Gotha, Schloßmuseum

Kopien und Varianten dieses Bildes bezeugen, daß es eines der wichtigsten Programmbilder des Protestantismus gewesen ist. Als solches ist es auch wohlbekannt, wie eine lange Reihe von Publikationen belegen kann, an deren Ende die Arbeit von Ohly steht. Trotz dieser Arbeiten sind entscheidende Fragen nach dem theologischen Gehalt dieser Bilderfindung bislang nicht überzeugend beantwortet worden, und es ist auch nicht versucht worden ihren historischen Ort in der Reformati-

51; Martin Luther und die Reformation in Deutschland, Katalog der Ausstellung im Germanischen Nationalmuseum Nürnberg 1983, Frankfurt a. M. 1983, 398ff.; Kunst der Reformationszeit, Katalog der Ausstellung im Alten Museum Berlin 1983, Berlin 1983, 357ff.; W. Hofmann (Hrsg.), Luther und die Folgen für die Kunst, Katalog der Ausstellung in der Hamburger Kunsthalle 1983/84, München 1983, S. 21off.; H. Belting, Bild und Kult. Eine Geschichte des Bildes vor dem Zeitalter der Kunst, München 1990, 522; Belting verwendet hier im onsgeschichte genau $\mathrm{zu}$ bestimmen ${ }^{17}$. Indem wir dies unternehmen, können wir die spezifische Argumentation dieses Bildes herausarbeiten.

Unser Ausgangspunkt für die Analyse dieses Bildtypus soll die 1529 datierte Fassung im Museum in Gotha sein (Abb. 3$)^{18}$. Die Bildmotive des Weimarer Altars finden wir hier in einem streng antithetischen Bildaufbau wieder. Links wird der nackte Mensch von Tod und Teufel in die Hölle getrieben. Moses, von einer Gruppe von Prophe-

Hinblick auf Cranachs Bild den Begriff "Argument «, ohne jedoch die Fragestellung der Argumentation weiter zu verfolgen.

${ }^{17} \mathrm{Am}$ weitesten gelangte hier: C. Harbison, The Last Judgement in Sixteenth Century Northern Europe. A Study of the Relation Between Art and the Reformation, New York/London 1976, 94ff.; vgl. auch W. Busch, Lucas van Leydens "Große Hagar " und die augustinische Typologieauffassung der Vorreformation, in: Zeitschrift für Kunstgeschichte, Jg. 45, 1982, I14ff. Ohly 


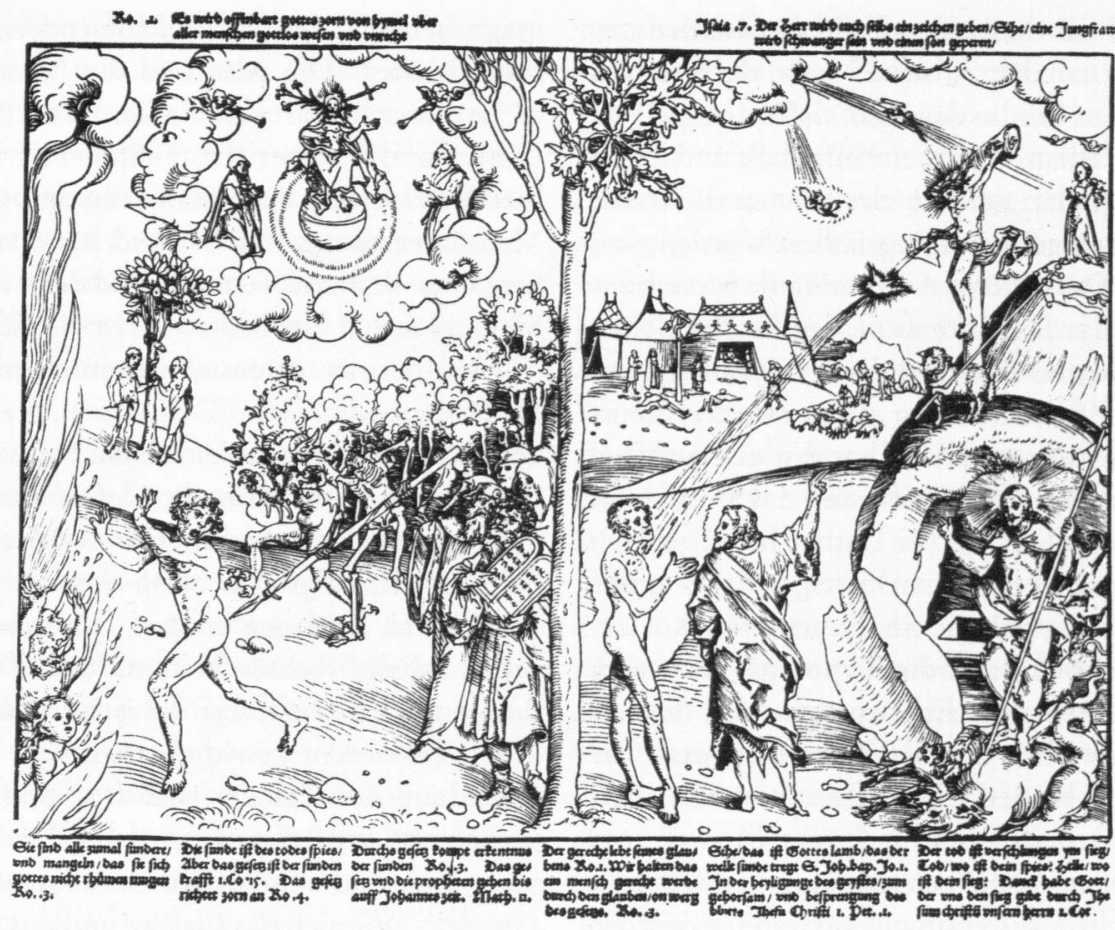

4. Lukas Cranach d. Ä., Gesetz und Evangelium, Holzschnitt, London, British Museum, Department of Prints and Drawings

ten begleitet, schaut zu und weist auf die Tafeln mit dem Dekalog. Den Hintergrund bilden die Szenen von Sündenfall und Eherner Schlange. Im Himmel erscheint der Christus des Gerichtes. Auf der rechten Tafel sieht man den nackten Menschen mit betend erhobenen Händen. Der Täufer weist ihn auf den Gekreuzigten, der vor dem offenen Grab dargestellt ist. Unten rechts steht das Lamm über den überwundenen Figuren von Tod und Teufel. Über dem Grab erscheint der gen Himmel

(Anm. 5), I6ff. hat die Bilderfindung Cranachs ganz aus der Theologie Luthers herzuleiten versucht und ist auf die Frage nach ihrem genauen historischen Ort der Reformationstheologie nicht weiter eingegangen.

${ }^{18}$ Gotha, Schloßmuseum: Friedländer/Rosenberg (Anm. 8), II4, Nr. 22I. Als ein Beispiel für die zahlreichen Varianten, die in Cranachs Atelier geschaffen worden sind, sei das Nürnberger Exemplar angeführt, das Mitte der dreißiger Jahre entstanden sein dürfte: Nürnberg, Germanisches Nationalmuseum; vgl. Ausst. Nürnberg 1983 (Anm. I5), 356, Nr. 474. fahrende Christus. Im Hintergrund erkennt man die Anbetung an die Hirten. In den Beischriften, allesamt Zitate aus der Bibel, wird die Darstellung kommentiert und im Sinne der protestantischen Maxime "sola scriptura" abgesichert ${ }^{19}$. Der Holzschnitt, der um 1530 in Cranachs Werkstatt entstand (Abb. 4), hat diese Verbindung von Text und Bild übernommen ${ }^{20}$.

Eine Frage, die sich bei der Zweiteiligkeit der Komposition geradezu aufdrängt, ist die, in wel-

${ }^{19}$ Die Texte auf den verschiedenen Fassungen sind nicht immer identisch, doch im wesentlichen übereinstimmend. Wiedergabe der Texte, die sich auf dem in zwei Exemplaren erhaltenen Holzschnitt Cranachs finden (Exemplar im Britischen Museum, London) in: Ausst. Nürnberg (Anm. 15), 398, Nr. 538.

${ }^{20}$ Der Holzschnitt ist nur in zwei Exemplaren erhalten. Exemplar im Britischen Museum London: Ausst. Nürnberg (Anm. I5), 398, Nr. 538. 
chem Verhältnis die beiden Teile zueinander stehen. Jean Wirth hat in seiner 1981 publizierten umfangreichen Studie das Bild als Antithese von Altem und Neuem Testament aufgefaßt und damit eine Ansicht, die auch in der älteren Literatur mehr oder weniger explizit geäußert worden war, bekräftigt ${ }^{21}$. Durchaus auf dieser Linie fortschreitend hat Ohly das Verhältnis der beiden Seiten ganz unter dem Gesichtspunkt der Typologie betrachtet. Es ist unbestritten ein großes Verdienst Ohlys und der neueren Forschung, die er zum Teil selbst initiiert hat, die Bedeutung des Fortlebens typologischen Denkens bei Luther herausgestellt $\mathrm{zu}$ haben und genauso unstrittig ist das große Gewicht der Typologie in diesem Werk Cranachs ${ }^{22}$. Dennoch kann die Typologie hier nicht das alles umfassende Erklärungsmodell liefern. Das zeigt sich schon daran, daß der Gegensatz der Hauptmotive beider Bildhälften, nämlich links der von Tod und Teufel gehetzte Mensch und rechts der auf den Gekreuzigten blickende Mensch, nicht als Typologie verstanden werden kann.

In der älteren Literatur ist Cranachs Bild sehr oft unter dem Titel sSündenfall und Erlösung‘ geführt worden ${ }^{23}$. Damit wurde eine Typologie herausgehoben, die hier tatsächlich gegeben ist, jedoch nicht im Vordergrund steht. Andere Titel sind >Gesetz und Gnade< oder >Gesetz und Evangeliumr. Diesen letztgenannten Titel hat Ohly konse-

${ }^{21} \mathrm{~J}$. Wirth, Le dogme en image: Luther et l'iconographie, in: Revue de l'Art, Nr. 5I, I98I, Isff.

${ }^{22}$ Ohly (Anm. 5), Iff. und die Nachweise 82ff., Anm. 3 und 4.

${ }^{23}$ So beispielsweise bei Friedländer/Rosenberg (Anm. 6), II 4 ; Schade (Anm. 8), 88.

${ }_{24}$ Ohly (Anm. 5), I8.

${ }^{25}$ Ohly (Anm. 5), 17 und Anm. 40 weist darauf hin, daß es sich bei der Gegenüberstellung von Sündenfall und Eherner Schlange um eine inneralttestamentarische Typologie handele, bei der letztere, als positiver Typus zur Kreuzigung, auf die Seite der Gnade gehöre. Das freilich ist, wenn man die Gesamtheit der "positiven « Typen im Alten Testament und ihre Verwendung betrachtet, wohl keine allgemein gültige Regel.

${ }^{26} \mathrm{Vgl}$. Melanchthons Loci communi von 152i: *Omne tempus, quod ad mentes nostras attinet, est legis atque evangelii tempus...*. Ph. Melanchthon, Werke in Auswahl, Herausgegeben von R. Stupperich, Güthersloh quent benutzt, der das Bild folgendermaßen charakterisierte: "Die Alte und die Neue Zeit sind dichotomisch klar geschieden. Dort Sündenfall, Gesetz und Strafgericht, Teufel, Tod und Hölle, hier Verheißung der Gnade für den Glauben..., Menschwerdung, Passion und Auferstehung mit Sieg über Tod und Teufel... und die Annahme des Sünders durch den Blutstrahl in die Gnade $\ll^{24}$.

Trotz der so offensichtlichen Antithetik der Bildkomposition, sind Deutungen, die von einem absoluten Gegensatz der beiden Seiten ausgehen, theologisch nicht adäquat. $\mathrm{Daß}$ die traditionelle Lehre der heilsgeschichtlichen Zeitalter hier nicht mehr greift, zeigt sich beispielsweise daran, daß die Eherne Schlange in den späteren Varianten meist auf der rechten Seite auftaucht ${ }^{25}$, während das Jüngste Gericht auf der Seite steht, die dem Alten Testament gewidmet sein soll. Die strikte Scheidung der Zeitalter sub lege und sub gratia wurde von den Reformatoren abgelehnt. Alle Zeiten waren und sind Zeiten des Gesetzes und der Gnade $^{26}$. Wie sich das Gesetz und das Gnade und Rechtfertigung verheißende Evangelium zueinander verhalten, war in den ersten Jahrzehnten der Reformation ein zentrales theologisches Problem, um das zum Teil heftig gestritten wurde. Die Bilderfindung Cranachs hat ihren historischen Ort in dieser Diskussion. Sie wurde unter dem Titel geführt, der auch der angemessene Titel für das Bild Cranachs ist: ২Gesetz und Evangelium

I95Iff., Bd. II/I, 66 (diese Ausgabe wird im folgenden zitiert als: Melanchthon StA; die Gesamtausgabe der Werke: $\mathrm{Ph}$. Melanchthonis Opera quae supersunt omnia, hrg. v. C. G. Bretschneider und H. E. Bildseil, 28 Bde., Halle/Braunschweig $1834-1860$ wird zitiert als: Melanchthon CR). Zum theologischen Problemkreis vgl. A. Peters, Gesetz und Evangelium (Handbuch systematischer Theologie, Bd. 2), Gütersloh 198I.

${ }_{27}$ Peters (Anm. 25), 29ff; P. Althaus, Die Theologie Martin Luthers, Gütersloh 1962, 218ff.

${ }^{28} \mathrm{M}$. Luther, Werke, Kritische Gesamtausgabe (abgekürzt zitiert als Luther WA), Weimar i883ff., Bd. 7, 502 (Enarrationes epistolarum et evangeliorum, quas postillas vocant, I52I); Luther WA, Bd. $40 /$ I, 209. Entsprechende Äußerungen finden sich noch vielfach in $\mathrm{Lu}$ thers Schriften, vgl. Peters (Anm. 25), 33 f.

29 Vgl. z. B. De Servo arbitrio (1525), Luther WA, Bd. i8, 766 und vorher schon in der Heidelberger Disputation von 1518 , Luther WA, Bd. $\mathrm{x}, 361$. 
Die Gegenüberstellung von Gesetz und Evangelium zieht sich wie ein roter Faden durch die Schriften Luthers und der frühen Reformatoren ${ }^{27}$. »Fast die ganze Schrift und die ganze Erkenntnis der Theologie hängen ab von der rechten Erkenntnis von Gesetz und Evangelium « konstatierte Luther IS2I und in seinem Kommentar zum Galaterbrief bezeichnete er die Unterscheidung von $\mathrm{Ge}^{-}$ set $z$ und Evangelium als "summa totius Christianae doctrinae $\ll^{28}$. Amt des Gesetzes ist es, so stellt er unter Berufung auf den Römerbrief des Paulus fest, Erkenntnis der Sünde zu bringen, den Zorn Gottes zu zeigen, während das Evangelium den Weg des Heils verkünde ${ }^{29}$. Das Gesetz deckte die Krankheit auf, das Evangelium gibt die Arznei « ${ }^{30}$. Die Antithetik des Cranach'schen Bildentwurfes, die Gesetz und Evangelium gleiches Gewicht gibt, entspricht allerdings nicht ganz der'Theologie Luthers und ihrer Konzentration auf das Kreuzesgeschehen $^{3 \mathrm{I}}$. Das Bildkonzept steht der Theologie Melanchthons weitaus näher ${ }^{32}$.

Melanchthon hat Luthers Gegenüberstellung von Gesetz und Evangelium aufgegriffen und verschärft. In seinen >Loci communes rerum theologicarum $<$ von 1521 , in denen er die Schlüsselbegriffe der Theologie erläutert ${ }^{33}$, hat er den Loci De Lege und De evangelio eine zentrale Stelle zugewiesen. Melanchthon fordert hier eine neue Art der religiösen Unterweisung. Die Scholastiker mit ihren Spekulationen über Gott, die Trinität und die Ge-

${ }^{30}$ Luther WA, Bd. Io/III, 338 (Sermon von den Heiltumen, I4. September 1522).

${ }^{31}$ In der Heidelberger Disputation von 1518 stellte Luther fest: »Ergo in Christo crucifixo est vera theologia et cognitio Dei « (Luther WA, I, 362); vgl. Althaus (Anm. 26), $34 \mathrm{ff}$.

${ }^{32}$ Dies vermutet auch Schade (Anm. 8), 74, ohne jedoch eine Begründung dafür zu geben. Überwiegend herrscht in der kunstgeschichtlichen Literatur jedoch die Ansicht vor, daß das Bildkonzept Luther zuzuschreiben sei.

${ }_{33}$ Text in Melanchthon St. A., Bd. II/I, 3 ff.; vgl. W. Maurer, Zur Komposition der Loci Melanchthons von Is2r. Ein Beitrag zur Frage Melanchthon und Luther, in: Luther-Jahrbuch I958, I46ff.; W. Maurer, Melanchthons Loci communes als wissenschaftliche Programmschrift, in: Luther-Jahrbuch 1960, Iff;; W. Maurer, Der junge Melanchthon zwischen Humanismus und Reformation, Bd. 2, 23off. heimnisse der Schöpfung hätten das Evangelium und die Wohltaten Christi verdunkelt. Den richtigen Weg habe Paulus gewiesen, der in seinen Briefen über Gesetz, Sünde und Gnade geschrieben habe: $\gg$ Denn aus diesen [sc. Begriffen] wird Christus eigentlich erkannt, weil Christus erkennen heißt: seine Wohltaten erkennen und nicht, wie jene [sc. die Scholastiker] lehren, seine Naturen oder die Formen seiner Inkarnation zu betrachten. Wenn du nicht weißt, zu welchem Zweck Christus Fleisch wurde und ans Kreuz geschlagen wurde, was nützt es dir dann, seine Geschichte zu kennen ${ }^{34}$.

Diese theologischen Grundbegriffe zu begreifen, ist also wichtiger, als die biblischen Geschichten zu kennen. Dieser Maxime folgte Melanchthon, als er 1527 von Johann von Sachsen den Auftrag zur Visitation der Kirchen im Lande erhielt, um die mit den Bauernkriegen aufgebrochenen Unruhen einzudämmen und die unübersehbaren Mißstände in den Pfarreien abzustellen ${ }^{35}$. Melanchthon hat in den Visitationsartikeln, die zunächst auf Latein und dann in erweiterter und von Luther durchgesehener Form auf deutsch erschienen, die Richtlinien für diese Aufgabe fixiert ${ }^{36}$. Besonderes Anliegen der Reformatoren war es, die Pfarrer anzuhalten, nicht nur von Glaube und Rechtfertigung $z u$ predigen, sondern auch von Gottes Zorn und von seinen Strafen, um zu Reue und Buße anzuhalten $^{37}$. »Denn rechter Glaube kan nicht sein, wo

$34 »$ Nam ex his proprie Christus cognoscitur, siquidem hoc est Christum cognoscere beneficia eius cognoscere, non, quod isti docent, eius naturas, modos incarnationis intueri. Ni scias, in quem usum carnem induerit et cruci affixus sit Christus, quid proderit eius historiam novisse* (Melanchthon StA, Bd. II/I, 7).

${ }_{35}$ Maurer (Anm. 32), Bd. 2, 47off.; M. Brecht, Martin Luther; Bd. 2: Ordnung und Abgrenzung der Reformation, Stuttgart 1986, 253ff.

${ }^{36}$ Melanchthon, Articuli de quibus egerunt per visitatores in regione saxoniae, Wittenberg I527, abgedruckt in: Melanchthon CR, Bd. 26, Sp. gff. Diese lateinische Version wurde ohne Zutun von Melanchthon gedruckt. Die »offizielle* Fassung ist: Unterricht der Visitatorn an die Pfarhern ym Kurfürstenthum zu Sachssen, I528, abgedr.: Melanchthon StA, Bd. I, $215 \mathrm{ff}$.

$37 \star$ Aber viel itzund sagen allein von vergebung der sunde, vnd sagen nichts odder wenig von Busse. So doch doch on busse keyn vergebung der sunden sit, Es kan auch 
nicht rechte Rewe ist, vnd rechte forcht vnd schrecken für Gott $\star^{38}$. Über die hier von Melan-

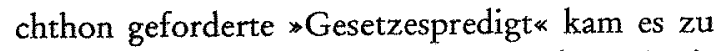
heftigen Auseinandersetzungen mit Johann Agricola, die auf einem Gespräch in Torgau durch einen Schiedsspruch Luthers nur oberflächlich beigelegt wurden 39 . Daß Melanchthon seine Ansichten in diesem Punkt nicht wesentlich revidierte, zeigen seine späteren Schriften ${ }^{40}$..

1529, im Jahr des Gothaer Bildes von Cranach, finden wir Melanchthons Auffassung wieder in den Schwabacher Artikeln, die ein wichtiger Schritt auf dem Weg zur >Confessio Augustanar waren. Der der Sünde verfallene Mensch und seine Rechtfertigung im Glauben an Christus werden hier in einer Weise gegenübergestellt, die an Cranachs Komposition erinnert: $\gg$ Nachdeme nun alle mennschen sunder seind, der Sunden vnnd dem todt, darzue dem teuffl unterworfen, ists vunmuglich, das sich ein mennsch auss seinen crefften oder durch seine gute werck herauß wurcke, damit er wider gerecht und frum werde. ... das aber ist der einige weg zur gerechtigkait vnnd zur erlosung von Sunden vnnd todt, So man on alle verdienst oder werck glaubt an den Sone gottes... solicher glawb ist vnser gerechtigkait « ${ }^{4 I}$. Der Glaube ist die Brücke zwischen der Sünde des Menschen und der Genugtuung Christi und dieser Glaube ist mein gottes werck vnnd gabe, die der heilig gaist durch christum gegeben In vnns wurckt $\ll$.

Nach diesem theologiegeschichtlichen Exkurs ist festzustellen, daß Cranachs Bild >Gesetz und Evangelium in einer Zeit entstand, in der es dar-

vergebung der sunden nicht verstanden werden on busse* (Melanchthon StA, Bd. I, 22I).

${ }^{38}$ Melanchthon StA, Bd. I, 243.

${ }^{39}$ Agricolas Vorwurf zielte vor allem darauf, daß Melanchthon die Buße aus der Furcht vor Strafe herleite, während sie doch aus der Liebe zur Gerechtigkeit fließe. G. Kawerau, Johann Agricola von Eisleben. Ein Beitrag zur Reformationsgeschichte, Berlin 188r, 140ff. Eine ausführliche Darstellung des Streites bei G. Hammann, Nomismus und Antinomismus innerhalb der Wittenberger Theologie von 1524-1530, Diss. Bonn 1952, $57 f f$. Die Gegensätze zwischen Luther und Melanchthon werden hier allerdings übertrieben gezeichnet; vgl. zum Verhältnis der beiden M. Greschat, Melanchthon neben Luther. um ging, die durch Bauernkriege und Schwärmertum erschütterte Reformation durch einen planvollen Neuaufbau der Kirche und durch eine systematische Fixierung der evangelischen Lehre zu sichern. Während Luther seinen Beitrag dazu mit dem >Bekenntnis< von 1528 und den beiden 1529 publizierten Katechismen leistete, die sich bewußt an Dekalog und Credo orientieren, systematisierte Melanchthon die Glaubenslehre in den Visitationsartikeln in einer Weise, die an seine schulmäßige Erörterung der theologischen Schlüsselbegriffe in den > Loci communes < anknüpfte, wenn auch auf einem schlichteren Niveau, das Rücksicht nahm auf den »gemeinen groben man $«$, an den die reformatorische Predigt sich richten sollte.

Die Systematik, mit der Melanchthon hier vorging, steht in der Tradition der Schulrhetorik und -dialektik. Diese wurde von ihm keinesfalls als »scholastisch $\ll$ verworfen, sondern in mehrfach neu bearbeiteten Lehrbüchern im Hinblick auf die Bedürfnisse der reformatorischen Unterweisung ausgebaut ${ }^{42}$. Bezeichnenderweise wurde von $\mathrm{Me}$ lanchthon den drei traditionellen genera der Rede (demonstrativum, deliberativum und iudicale) ein genus didascalicum hinzugefügt, mit der Begründung, »weil dieses genus in dieser Zeit besonders großen Nutzen in den Kirchen hat, so weniger Beratungsreden zu halten sind, als viel häufiger die Menschen nach den Regeln der Dialektik über die Dogmen der Religion zu unterrichten sind, damit sie diese richtig begreifen können « 43 .

Als Beispiel für dieses genus didascalicum gibt Melanchthon das Schema einer Rede, die auf die

Studien zur Gestalt der Rechtfertigungslehre zwischen is 28 und 1537, Witten 1965. Die Auseinandersetzungen brachen 1537 im sogenannten antinomistischen Streit wieder auf, vgl. Kawerau (wie oben), $168 f f$.

$4^{\circ}$ Beispielsweise die >Apologia confessionis Augustanae von 1531: $»$ Haec enim sunt duo praecipua opera Dei in hominibus, perterrefacere, et iustificare ac vivificare perterrefactos. In hac duo opera distributa est universa scriptura. Altera pars lex est, quae ostendit, arguit et condemnat peccata. Altera pars evangelium, hoc est promissio gratiae in Christo donatae, et haec promissio subinde reperitur in tota scriptura...*. (J. T. Müller, Die symbolischen Bücher der evangelisch-lutherischen Kirche, 7. Aufl. Gütersloh I890, 175). 


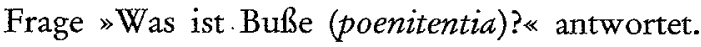
Ich möchte einige Punkte daraus anführen, weil sie helfen können, die Argumentation in Cranachs Bild nachzuvollziehen. An Anfang steht die Worterklärung: Buße ist die Hinwendung des Willens zur wahren Frömmigkeit (pietas). Der Definition nach besteht Buße (2.) aus Reue (contritio) und Glaube. (3.) Die Reue besteht aus Erkenntnis der Sünden und Schrecken und Schmerz über die Sünden. (4.) Der Glaube richtet die erschütterte Seele wieder auf und tröstet sie im Empfang der Vergebung der Sünden. (5.) Ursachen der Buße sind das Gesetz, das die Sünden bloßstellt, und der Heilige Geist, der im Gesetz wirkt und den Willen antreibt. (6.) Ursache des Glaubens sind das Evangelium, das die Vergebung um Christi willen verkündet und der durch das Evangelium wirkende Heilige Geist. (7.) Mit der Reue ist die Tugend der Gottesfurcht verbunden, mit dem Glauben Hoffnung und Liebe (dilectio). (8.) Die Folgen wahrer Buße sind ein neues und geistliches Leben, fromme Werke (pia opera) und die Erwartung des Ewigen Lebens ${ }^{44}$.

Cranachs >Gesetz und Evangelium < entspricht in seiner Anlage der Systematik, die Melanchthon seit seinen $>$ Loci communes entwickelt hatte. Die linke Seite stellt die dem locus de lege zuzuordnenden Begriffe dar: die Erbsünde, der im Jüngsten Gericht drohende Zorn Gottes, der von Tod und Teufel getriebene Mensch, dem seine Sündhaftigkeit durch das Gesetz aufgezeigt wird, seine Verzweiflung und Reue. Rechts dagegen der Begriffskreis des locus de evangelio: durch den Täufer

${ }^{41}$ Luther WA, Bd. 30/III, 88; zur Autorschaft oder Mitautorschaft Melanchthons vgl. ebd. 83. Ausführlich dazu Greschat (Anm. 38), 2off.

${ }^{42}$ Die Erstfassung des Lehrbuches der Rhetorik war: De rhetorica libri tres, Wittenberg I519; mir stand die Neubearbeitung von I53r im Druck von 1542 im Original und im Abdruck im Corpus Reformatorum, Bd. XIII, Halle 1846, 4Ifff. zur Verfügung; ihr Titel: Elementorum Rhetorices libri duo. Melanchthons Lehrbuch der Dialektik erschien in erster Fassung 1520 unter dem Titel: Compendiaria Dialectices ratio, Leipzig I520. Die Neuauflage Is2I abgedruckt in: Corpus Reformatorum, Bd. XX, 1854, 7Irf. Eine erheblich erweiterte Fassung erschien unter dem Titel: Erotemata dialectices, Witten- wird der Mensch auf Christus verwiesen: mit der Geste des Glaubens steht er da. Seine Hinwendung zum Erlöser hat ihr Korrelat in dem Blutstrahl, der aus dessen Seitenwunde hervorspringt und in dem die Taube des Heiligen Geistes erkennbar ist: die Rechtfertigung im Glauben ist Gabe des Heiligen Geistes. Die Wirkungen des Opfertodes sind die Überwindung von Tod und Teufel, durch das symbolische Lamm vollzogen, und die Himmelfahrt, durch die dem Gläubigen der durch die Versöhnung und die Vergebung der Sünden eröffnete Weg zu Gott gezeigt wird. Wenn auf späteren Darstellungen wie dem Holzschnitt aus Cranachs Atelier die Darstellung der Ehernen Schlange in die rechte Bildseite verlegt wird, so ist das nur konsequent, weil dieses Ereignis ein Akt der Verheißung und Erlösung war, genau wie die Verkündigung Mariens und die Verkündigung an die Hirten ${ }^{45}$.

Die offensichtliche Identität der männlichen Aktfigur in den beiden Bildhälften bietet dem Betrachter einen ersten Anhaltspunkt für die Erfassung der Bildaussage. Diese Figur, die gemäß der biblischen Metaphorik als Adam, als Mensch schlechthin verstanden werden kann, zeigt sich in den beiden Bildteilen in so unterschiedlicher Befindlichkeit, daß sich die Frage nach den Gründen dafür geradezu aufdrängt. Die scheinbar disparaten Einzelmotive erweisen sich bei genauerer Betrachtung als eine Kette von Aussagen, die sich vom Rezipienten zu einem Syllogismus zusammenfassen lassen, wobei Art und Anordnung der Motive einen bestimmten Schluß präsupponieren.

berg 1547, abgedruckt in: Corpus Reformatorum, Bd. XIII, Halle ז846, 513ff.

${ }^{43}$ Melanchthon, Elementa rhetorices: Das didascalicum genus »non est praetermittendum, praesertim, cum hoc tempore vel maximam usum in Ecclesiis habeat, ubi non tantum suasoriae conciones habendae sunt, sed multo saepius homines dialecticorum more de dogmatibus religionis docendi sunt, ut ea perfecte cognoscere possint* (Melanchthon CR, Bd. I3, Sp. $421)$.

44 Paraphrasiert nach Elementa Rhetorices, Melanchthon CR, Bd. 13, Sp. 425f.

${ }^{45}$ Melanchthon, De Lici communes, StA, Bd. II/I, 85 führt die Eherne Schlange im Kapitel "De vi evangelii* an. 
Das Nachvollziehen dieser Argumentation kann beispielsweise so lauten: der Mensch wird von Tod und Teufel in die Hölle getrieben. Dies geschieht trotz der Anwesenheit des Gesetzes, also taugt das Gesetz nicht zu seiner Rettung. Dagegen gestellt wird rechts die Rechtfertigung: der gläubig auf Christus blickende Mensch kann beruhigt sein, weil die ihn bedrohenden Mächte Tod und Teufel durch Christus als Opferlamm überwunden sind. Daß der gen Himmel schwebende Christus hier nicht mehr wie links im Gericht droht, sondern ihn auf Gott verweist, darf als Zeichen der Rechtfertigung aufgefaßt werden. Der beide Bildteile umspannende Syllogismus lautet: Der Mensch wird von Tod und Teufel in die Hölle getrieben. - Christus hat durch seinen Opfertod Tod und Teufel überwunden. - Also ist der Mensch durch Christus von der ewigen Verdammung erlöst.

Neben diesem Hauptgedanken sind verschiedene Motive zu entdecken, die weitere Argumente hinzufügen, beispielsweise der Baum, der auf der Seite des Gesetzes kahl ist, auf der des Evangeliums jedoch grünt ${ }^{46}$ : das Evangelium verheißt Leben und Hoffnung. Auch die typologischen Beziehungen, die Ohly vor allem herausgestellt hat, sind als besondere Form der Argumentation aufzufassen. Gott ließ Moses die Eherne Schlange als Zeichen des Heils errichten: Wer auf die Schlange blickte, wurde errettet. Christus ist als Antitypus das neue Zeichen des Heils. Die conclusio daraus

${ }^{46} \mathrm{Vgl}$. Busch (Anm. 16), rorff.

47 Das bedeut und zeigt an, was der glaub thuett, und wie er geschickt sein soll. Die erene Schlang, die auff dem pfal hengt, ist Christus ans Creutz geschlagen * (Luther WA, Bd. 9, 659); vgl. Ohly (Anm. 5), gff.

$4^{8} \mathrm{~A}$. Peters, Rechtfertigung (Handbuch systematischer Theologie, Bd. I2), Gütersloh $1984,66$.

49 Prag, Nationalgalerie; Thulin (Anm. 8), 132ff.

${ }^{50}$ Diese These vertrat mit Nachdruck Busch (Anm. 16), 116.

${ }^{51}$ Geogroy Tory, Gesetz und Gnade, Holzschnitt, Exemplar in Paris, Bibliothèque Nationale; vgl. Ausst. Hamburg (Anm. 15), Nr. 86, 212.

${ }^{2}$ A. M. Göransson, Livsträdet och Geofroy Tory, in: Tidskrift för Konstvetenska, Bd. 30, 1957, 59ff.; Busch (Anm. 16), 115ff.

${ }^{53}$ Die einzige Monographie über Tory (ca. 1480 - ca. 1533) nach wie vor: A. Bernard, Geofroy Tory, Peintre et ist, daß gerettet werden wird, wer auf den Gekreuzigten blickt ${ }^{47}$.

Die in den Bildern Cranachs als Blick auf den Gekreuzigten veranschaulichte Glaubensbeziehung des Menschen zu Christus hat, wie gesagt, ihre Korrelat in dem Blutstrahl aus der Seitenwunde Christi. Wenn in diesem Strahl das Symbol des Geistes erscheint, wird damit eine Aussage formuliert, die von der traditionellen sakramentalen Auffassung des Blutes abweicht: Rechtfertigung ist Gnaden wirkung des Gottesgeistes, wie Melanchthon in seinen $>$ Loci communes $<$ darlegt ${ }^{48}$. Hier ist noch der Hinweis auf ein anderes Argument anzuschließen, das als argumentum ex silentio zu bezeichnen ist. Der Mensch wird hier gerechtfertigt, ohne daß er anderes tut, als diese Gabe im Glauben anzunehmen, Voraussetzung der Rechtfertigung sind also nicht die guten Werke, wie es die katholische Kirche lehrt, sondern die Rechtfertigung erfolgt, in der Terminologie der Reformatoren gesprochen, sola fide.

In dem Bild Cranachs ist, so können wir feststellen, ein Argumentationssystem ausgebreitet, das zentrale Begriffe der protestantischen Theologie: Gesetz und Evangelium, Gottes Zorn und Gnade, Buße, Glaube und Rechtfertigung umfaßt. Natürlich ist es nicht möglich, diese Begriffe vom Bild her theologisch fundiert zu entwickeln, aber sie können doch vor dem Bild systematisch dargelegt und erläutert werden. Das Bild konnte für die religiöse Unterweisung der Laien eingesetzt wer-

graveur, Premier Imprimeur royal, réformateur de Porthographie et de la typographie sous François Jer, Paris I865. Zu dem in Rede stehenden Holzschnitt ebd., $324 f f$. Vgl. ferner: R. Mortimer, French Sixteenth Century Books (Harvard College Library, Department of Printing and Graphic Arts. Catalogue of Books an Manuskripts, vol. I), Cambridge-Mass. 1964; M. Dickman Orth, Geofroy Tory et l'enluminure. Deux livres d'Heures de la collection Doheny, in: Revue de l'Art Nr. 50, 1980, 4off. Göransson (Anm. 5I), 68f. datiert Torys Holzschnitt vor allem mit dem Hinweis auf den stilistischen Zusammenhang mit Torys Holzschnittserie der >Taten des Herkules<, jedoch sind auch diese Holzschnitte nicht fest datiert. Die von Bernard a.a.O., 246 angegebene Entstehungszeit ist lediglich eine Vermutung, die auf der besonderen Form des Monogramms in diesen Holzschnitten basiert. Dieses Monogramm taucht jedoch in unserem Holzschnitt nicht auf. 
den und den Gläubigen dazu dienen, die loci communes ihres Glaubens zu rekapitulieren. Als protestantisches Lehrbild war die Bilderfindung Cranachs damals konkurrenzlos und hat deswegen, wie anfangs erwähnt, größte Verbreitung gefunden.

Eine Argumentation, so originell sie auch sein mag, wird sich stets zum guten Teil vorgefundener Argumente bedienen und ihre Originalität besteht oft genug nur darin, daß sie vorgegebene Argumentationssysteme neu ordnet. So ist es auch bei Cranachs >Gesetz und Evangelium<. Im gleichen Jahr I529, in dem Cranach das erläuterte Gothaer Bild malte, entstand in seiner Werkstatt eine andere Fassung, die sich heute in Prag befindet (Abb. 5) ${ }^{49}$. Es spricht einiges dafür, daß dieser Prager Typus dem Gothaer Typus vorausging ${ }^{50}$. Ein ungelöstes Problem jedoch ist die Frage, wie sich Cranachs Prager Bild zu dem Holzschnitt des Franzosen Geofroy Tory verhält, der in der Komposition mit ihm weitestgehend übereinstimmt (Abb. 6) ${ }^{\text {s. }}$. Göransson und Busch vertraten die Ansicht, daß Torys Werk das frühere sei und ihm mithin das Verdienst der Erfindung dieser überaus erfolgreichen Bildprägung zukomme ${ }^{\text {s2 }}$. Es gibt jedoch keine wirklich sicheren äußeren oder stilistischen Anhaltspunkte für eine Datierung, da das Werk Torys bislang nur höchst unvollkommen erforscht ist ${ }^{53}$. Es muß also inhaltlich argumentiert werden, und da möchte ich entgegen der These von Busch an der herkömmlichen Ansicht festhalten, die Cranach die Erfindung dieser Kompositi-

Dieser ist lediglich mit einem kleinen lothringischen Kreuz »signiert« (rechts, unterhalb des Schildes $»$ Lenseigneur du Christ $*$ ), das man auch in Torys spätesten Werken findet.

Die Zahlen in dem Holzschnitt weisen darauf hin, daß dieser ursprünglich als Illustration zu einem Text konzipiert war. Leider hat sich dieser Text bislang nicht nachweisen lassen.

${ }^{54}$ Busch (Anm. 16), Irs fragt rhetorisch: »was sollte dem gebildeten Humanisten Tory dazu bewegen, nun gerade ein ausgewiesenes protestantisches Exempel weiter auszuspinnen?* Dem wäre entgegenzuhalten, daß Tory seinen Holzschnitt wohl kaum auf eigene Initiative hin geschaffen hat, sondern im Auftrage anderer als Illustration zu einem vorliegenden Text. Es ist durchaus denkbar, daß dieser Text kontroverstheologisch on zuschreibt, weil sie grundsätzlich reformatorisch gedacht ist und von daher eine Entstehung im Umkreis Luthers am wahrscheinlichsten bleibt ${ }^{54}$.

Das Prager Bild wird in der kunstgeschichtlichen Literatur gewöhnlich als Variante des Gothaer Typs bezeichnet, jedoch kann schon eine flüchtige Betrachtung nicht unwichtige Auffassungsunterschiede aufzeigenss. Im Prager Bild fehlt die Darstellung des Gerichtes wie die Bedrohung des Menschen durch Tod und Teufel und damit jene Elemente, die die von Melanchthon geforderte Gesetzespredigt ausmachen. In dieser Fassung steht der Mensch im Mittelpunkt, der nackt am Boden sitzt, eben noch dem offenen Grab zugewendet, jetzt aber durch Prophet und Täufer auf Christus verwiesen ${ }^{56}$. Das Bild konfrontiert Sündenfall und Tod, die dem Gesetz zugeordnet werden, mit Gnade und Rechtfertigung57. Im Lichte der ikonographischen Tradition betrachtet, ist das Motiv des Todes höchst ungewöhnlich. Es verweist auf die Theologie, die Paulus in seinen Briefen entfaltet hat und mit der sich Luther in den entscheidenden Jahren der reformatorischen Wende so intensiv befaßte. Der Text unter dem Bild zitiert die entscheidenden Stellen, beispielsweise »Der Tod ist der Sünden Sold « (Römer 6, 23). Paulus folgend stellte Luther Gesetz und Evangelium einander gegenüber als " ministerium mortis « und »ministerium spiritus $\aleph^{58}$. Das Gesetz führt in den Tod, das Evangelium verkündet das ewige Leben.

war, also sich aus katholischer Perspektive mit den Auffassungen der Lutheraner auseinandersetzte und sie zu widerlegen versuchte.

55 Dies betont auch Ohly (Anm. 5), 2rf.

56 In der Schriftzeile unter den Figuren lautet von links nach rechts: "TODT - PROPHETEN - MENSCH AN [d. h. ohne] GNAD - ANZEIGER CHRISTI VNSER VBERWINDVNG*. Der Prophet wird also nicht benannt. Die Figur steht mithin wohl für alle Propheten, ist also nicht, wie Ohly (Anm. 5) 2I annimmt, mit Jesaias zu identifizieren.

57 Die Beschriftung des Prager Bildes nennt oben links »GESECZ* und oben rechts $* G N A D *$. Um dieses Bild vom Gothaer Typus abzusetzen, sollte man ihm den Titel > Gesetz und Gnade geben.

${ }^{58}$ Luther WA, 39/I, 447; vgl. Althaus (Anm. 26), 223. 


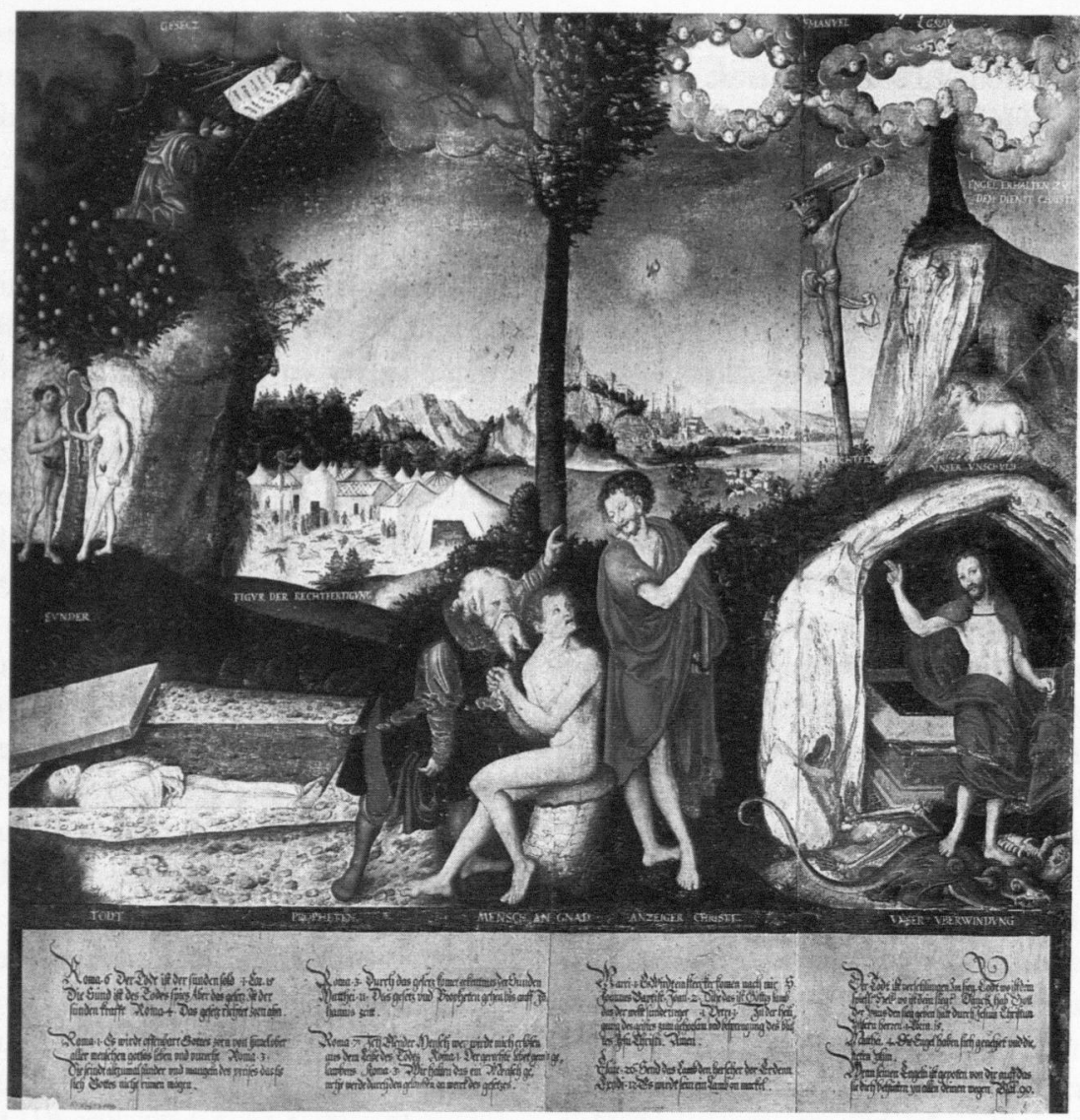

5. Lukas Cranach d. Ä., Gesetz und Gnade, Prag, Národni Galerí

Wenn man von der Mittelfigur des Menschen ausgeht, so ist das Thema des Bildes die Anfechtung, die den Menschen im Anblick des Todes befällt und seine Erlösung durch Christus. Es thematisiert mithin ein theologisches Problem, mit dem sich Luther in den Anfangsjahren der Reformation mit besonderer Intensität auseinandersetzte ${ }^{59}$. Es mahnt und tröstet wie Luthers >Sermon von der Bereitung zum Sterben von I5I9:

$59 \mathrm{H}$. Beintker, Die Überwindung der Anfechtung bei Luther. Eine Studie zu seiner Theologie nach den >operationes in Psalmos 1519-1521, Berlin I954.

${ }^{60}$ Luther WA, Bd. 2, 690. Luther führt in diesem Kontext auch das Bild der Ehernen Schlange an.

${ }^{61}$ Luther WA, 5, 608 (Operationes in Psalmos, 1519-2I); Übersetzung nach Luther/Walch, Bd. ${ }_{4}$, Sp. 124I. Zur
"Du must den nit yn yhm selbs, noch yn dir odder deyner natur... ansehen odder betrachten, ... Sondern deyn augen, deyns hertzen gedancken unnd alle deyne syn gewaltiglich keren von dem selben bild, und den todt starck und emsig ansehen nur yn denen, die yn gottis gnaden gestorben und den todt ubir wunden haben, furnemlich yn Christo. [...] Das ist gnade und barmhertzigkeit, das Christus am Creutz deyne sund von dir nymmet, tregt

katholischen Position, die endgültig 1547 auf der 6. Sessio des Tridentiner Konzils formuliert wurde: $\mathrm{H}$. Rückert, Die Rechtfertigungslehre auf dem Tridentiner Konzil, Bonn 1925, z. B. 116: "So stellt der 6. Canon das Verhältnis der in der Rechtfertigung verliehenen Gerechtigkeit Christi mit den Worten dar: nicht der actus iustitia werde unser actus. Der bleibe natürlich in Chri- 


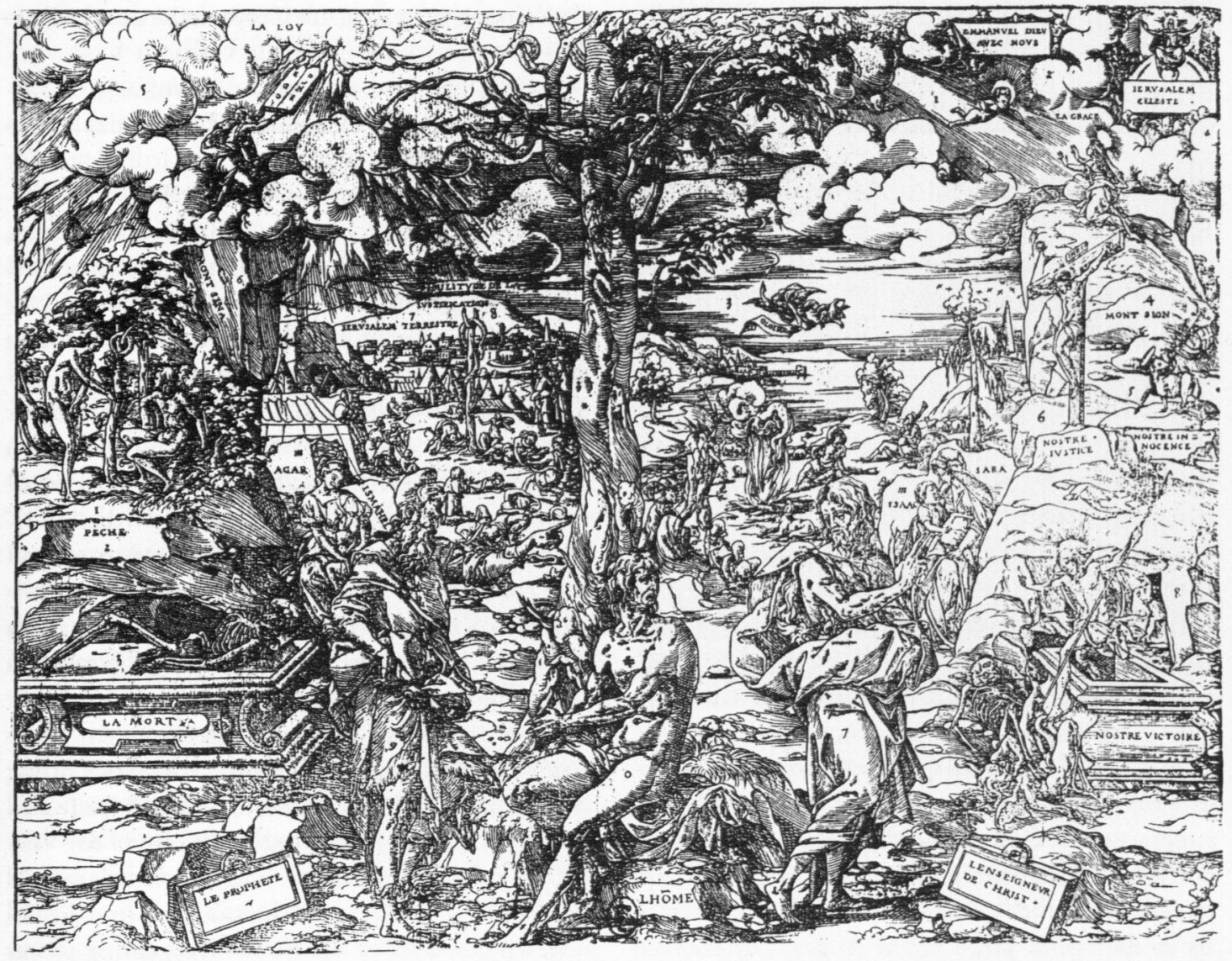

6. Geofroy Tory, Gesetz und Gnade, Holzschnitt, Paris, Bibliothèque Nationale

sie fur dich und erwurget sie ${ }^{60}$. Die Beschriftung des Bildes: "VNSER RECHTFERTIGVNG « unter dem Kruzifix, »VNSER VNSCHVLD « unter dem Lamm und "VNSER VBERWIN DVNG « unter dem auferstehenden Christus verweist auf jene Auffassung der Rechtfertigung, die ein zentraler Glaubenssatz der Reformation war und die Luther unter anderem in seinem GalaterKommentar dargelegt hatte: »Und dies ist das rei-

stus. Vielmehr werde uns ein habitus iustitae verliehen, den Christus uns durch seine Gerechtigkeit verdient habe«.

${ }^{62} \mathrm{Vgl}$. dazu auch Ohly (Anm. 5), 1oof., Anm. 56, der in der philologisch nicht korrekten Übersetzung auf dem französischen Holzschnitt ein weiteres Argument für die Priorität Cranachs sieht. Wenn Busch (Anm. I6), IIs che Geheimniß der göttlichen Gnade gegen den Sünder, daß durch einen wunderlichen Wechsel unsere Sünden nun nicht mehr unsere, sondern Christi Sünden sind, und die Gerechtigkeit Christi nicht Christi, sondern unsere Gerechtigkeit ist « ${ }^{6 \mathrm{I}}$. $\mathrm{Daß}$ sich diese Worte auch auf dem Holzschnitt Torys wiederfinden, spricht meiner Überzeugung nach dafür, daß sein Werk eine protestantische Vorlage hat ${ }^{62}$. Ob gerade das Prager Bild die un-

Torys Holzschnitt als »eine in sich gänzlich konsequente typologische Demonstration der Bezüge zwischen Altem und Neuem Testament « bezeichnet, so ist dies nicht ganz richtig, weil das konstitutive Motiv von Grab und Tod auf der linken Seite in der traditionellen Typologie keinen Platz hätte. 
mittelbare Vorlage war, mag dahingestellt sein. Man wird auch mit der Möglichkeit rechnen müssen, daß diesem. Werkstattbild eine frühere Version aus der Hand Cranachs vorausging ${ }^{63}$.

Während das Gothaer Bild die Auffassung Melanchthons veranschaulicht, dürfen wir den Prager Typus mit den Anschauungen Luthers aus der Frühzeit der Reformation zusammenbringen. Der Schritt vom Prager zum Gothaer Typus ist $\mathrm{zu}$ kennzeichnen als Umgruppierung einzelner Argumente, die zwar nicht auf eine grundsätzlich neue Argumentation abzielt, aber doch den für Melanchthon wichtigen Aspekt von Gesetz und Zorn Gottes heraushebt und damit die Gewichte nicht unerheblich verschiebt ${ }^{64}$.

Auch der Prager Typus hat, wie in der Literatur ausführlich nachgewiesen wurde, seine eigene Nachfolge gehabt. Ein Gemälde Hans Holbeins und Erhard Altdorfers 'Titelblatt zur niederdeutschen Bibel von 1533 sind hier vor allem anzufüh$\mathrm{ren}^{65}$. Daß sich letztlich aber nicht dieser frühere Typus, sondern der des Gothaer Bildes durchsetzte, wird man mit den neuerlichen Auseinandersetzungen um die Gesetzespredigt zusammenbringen dürfen, dem sogenannten Antinomistenstreit, der I 537 ausbrach und in dem sich Luther entschiedener als er dies zehn Jahre zuvor in den Differenzen zwischen Melanchthon und Agricola getan hatte, gegen alle diejenigen wandte, die wie Agricola die

${ }_{6}^{6}$ Einen Hinweis auf protestantisches Denken darf man wohl auch in der Beischrift $»$ Emanuel erkennen, die rechts oben neben dem vom Himmel herabschwebenden kreuztragenden Christuskind zu erkennen ist und die auch Tory übernommen hat. Es ist ein Verweis auf die Prophezeiung des Jesaias (Jes. 7,I4), die Matthäus aufgegriffen hatte: $*$ Das ist aber alles geschehen/ Auff das erfüllet würde/ das der HERR durch den Propheten gesagt hat, der da spricht/ Sihe eine Jungfraw wird schwanger sein und einen Son gebern/ und sie werden seinen Namen Emanuel heissen/ das ist verdolmetscht/ Gott mit uns* (Matth. I, 22/23). Anders als die Ostkirche, die einen eigenen Christus-Immanuel-Typus prägte, hat die abendländische Kirche mit dem Namen wenig anfangen können. Eine Ikonographie des Immanuel hat sie nicht ausgebildet. Sie hat die Prophezeiung des Jesaias hauptsächlich als Zeugnis für die jungfräuliche Geburt angeführt. Kommentare wie der des Nicolaus von Lyra geben dieser Stelle kein besonderes Gewicht. Luther hingegen hat sich mit der Bedeutung des $\mathrm{Na}-$ mens *Emanuel* (heute stets: Immanuel) mehrfach
Auffassung vertraten, das Gesetz habe durch Christus seine geistliche Funktion verloren ${ }^{66}$.

Es entsprach also durchaus der Auffassung Luthers, wenn der Gothaer Typus des Cranach'schen Programmbildes zur Grundlage der Darstellung auf dem Mittelbild des Weimarer Altares gewählt wurde, wenn auch hier das Gesetz, das »Zorn schafft $\ll$, das die Sündhaftigkeit bloßstellt, gezeigt wird. Allerdings geschieht dies hier nicht gleichberechtigt neben der Verbildlichung des Evangeliums, sondern im Hintergrund, jedoch keineswegs beiläufig, vielmehr genau in der Bildmitte. Mit dieser Versetzung der ursprünglich nebeneinander stehenden Bildteile auf die Tiefenachse des Bildraumes kommt eine zeitliche Dimension in die Aussage. Die »Gesetzespredigt* tritt zurück, nicht in dem Sinne, daß hier das Zeitalter des Gesetzes überwunden wäre, sondern im Sinne der religiösen Biographie der heimlichen Hauptfigur, nämlich Lucas Cranachs. Er, den wir auch in dem von Tod und Teufel gejagten Menschen wiedererkennen können, hat Anfechtung und Sünde hinter sich gelassen, ist durch Buße und Reue hindurchgegangen und steht nun in der Verheißung des Evangeliums: weil der Gnadenstrahl des Blutes ihn trifft und Christus Tod und Teufel überwindet, darf er der Sündenvergebung sicher sein. In dieser Glaubensgewißheit wird er gestützt durch den Täufer, der auf den Gekreuzigten wie

auseinandergesetzt, beispielsweise in seiner Predigung zum Tag der Verkündigung Mariae 1532: »Das heist Emanuel. Si solus diceretur deus, nihil consolaretur. Sed got myt und bey uns, unser fleysch und blut haben, nicht myt den engeln, hoc consolaretur. Nos autem sumus damnati, captivi peccato. Nomen nostrum ab Adae Szunde: tod, teuffel myt uns, Gott fern von uns. Deus est in celis, nos in inferno, secundam primam nativitatem dicitur: Got ferne von uns und wyr von yhm. Nunc mutatur nomen: Got myt und bey uns. Sequitur: >si deus pro nobis<, inquit Paulus ec., >quis contra nose? nam sumus illi reconciliati. Tam sequitur: Szunde, Teuffel, todt ferne von uns, Got, Gnade, fridt, heylickeyt bey uns. Das heyst Emanuel « (Luther WA, Bd. 36, r5of;; vgl. auch die Predigt vom 24. Dezember 1528: Luther WA, Bd. 27, 479ff.). Es ist unübersehbar, daß diese Auffassung der Prophezeiung des Jesaias sich bestens in das theologische Gesamtkonzept des Cranach-Bildes fügt.

${ }_{64}$ Wirth (Anm. 20), Ifff. stellte die These auf, daß der Gothaer Typ des Bildes die Auffassung Luthers vertrete, 
auf das Lamm zeigt und durch Luther, der korrelativ dazu auf die Schrift weist. Beide zusammen werden eingesetzt als argumentum ab autorita$t e^{67}$, das auch den Betrachter in seiner Religion stärken soll.

Die in diesen Bildern Cranachs zu beobachtenden Argumentationsformen sind nur ein Teil der Möglichkeiten dieser Bildgattung. Nach den Lehren der Schulrhetorik und -dialektik, von denen man voraussetzen darf, daß sie im Denken der Zeit fest verankert waren, gab es zwei grundsätzliche Möglichkeiten der Argumentation, nämlich nach der von Cicero vorgeschlagenen Systematisierung - ratiocinatio und inductio: das logische Schließen und das Induzieren. Logische Schlußformen sind der Syllogismus in seinen verschiedenen Spielarten und das Enthymem, Formen der inductio der Induktionsschluß und das Exempel ${ }^{68}$.

Um die hier gegebenen Möglichkeiten wenigstens anzudeuten, möchte ich einige weitere Beispiele für verschiedene Formen der Bildargumentation vorführen, wobei ich die Reformationszeit nicht verlasse. Cranachs >Gesetz und Evangelium ‘ war in seinem Kerngedanken als Syllogismus aufzufassen. Unter den Oberbegriff der ratiocinatio ist auch das 1522 von Hans Schäufelein gemalte Bild des Schmerzensmannes zu stellen, das aus der Nördlinger St. Georgskirche stammt (Abb. 7$)^{69}$.

der Prager Typ hingegen jene Melanchthons. Der erste Fehler seiner Interpretation liegt, wie oben schon erwähnt, darin, daß er das Bild als eine Antithese der heilsgeschichtlichen Zeitalter versteht und in Entsprechung zur Tradition der Entgegensetzung von Ecclesia und Synagoge. Von daher kommt er is zu der Behauptung: "Dans le tableau de Gotha, le pécheur est irréstiblement damné et le croyant est irréstiblement sauvé«. Daraus schließt er, daß hier das Gesetz das »instrument de la damnation« und das Programm des Bildes radikal antinomistisch sei, während der Prager Typus, in dem die Motive von Gericht, Tod und Teufel eliminiert wurden, entschieden nomistisch sei. Damit werden die theologiegeschichtlichen Positionen geradezu in ihr Gegenteil verkehrt und es wird noch ärger, wenn Wirth die von im als "antinomistisch « deklarierte Fassung als Werk Luthers bezeichnet (»On ne peut assurer que Luther ait dicté le modèle de Gotha un beau jour de 1529") und Luther als "Antinomisten « bezeichnet, was völlig unhaltbar ist und zwar nicht erst im Hinblick auf Luthers Haltung im Antinomistenstreit; vgl. unten Anm. 65.

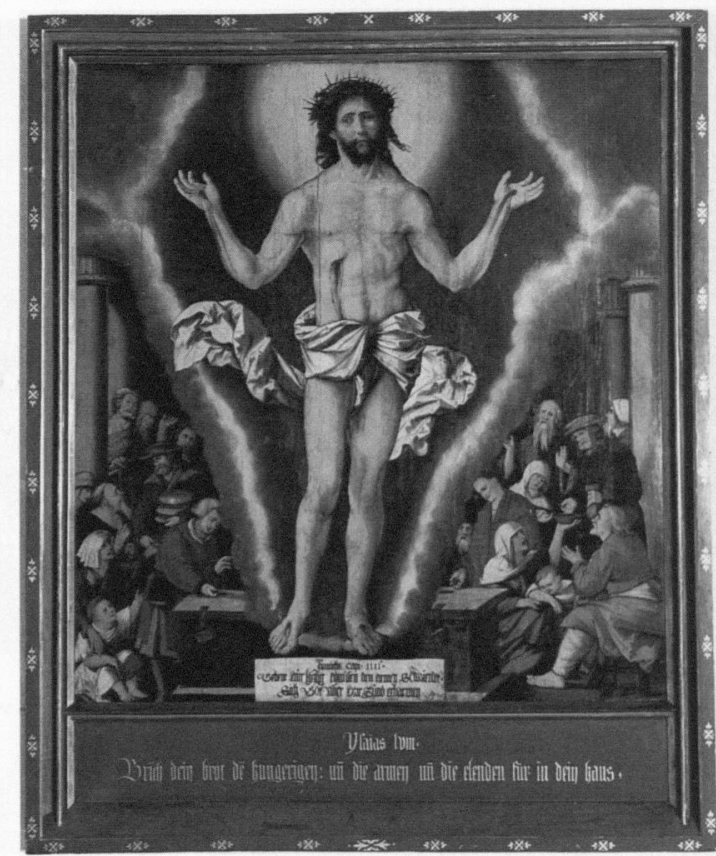

7. Hans Schäufelein, Schmerzensmann über dem Almosenkasten, Nördlingen, Stadtmuseum

Das Bild hat einen sehr konkreten Anlaß. Mit der Einführung der Reformation wurde vielerorts die von der Kirche getragene Armenpflege zu einem Problem, weil die Einkünfte ausblieben. So auch in Nördlingen, wo man sich 1522 eine Almosen-

${ }_{65}$ Vgl. Thulin (Anm. 8), I39f.; Ausst. Hamburg (Anm. 15), 2 I2.

${ }^{66}$ Kawerau (Anm. 38), 18Iff.; R. Hermann, Zum Streit um die Überwindung des Gesetzes. Erörterungen zu Luthers Antinomerthesen, Weimar 1958; die wichtigsten Texte zur Position Luthers in seinem Streit gegen die "Antinomer in Luther WA, Bd. 39/1, 342ff.

${ }^{67} \mathrm{Vgl}$. Melanchthon, Erotemata dialectices: Melanchthon CR, Bd. 13 , Sp. $707 \mathrm{ff}$.

68 \#Omnis igitur argumentatio aut per inductionem tractanda est aut per ratiocinatio « (Cicero, De inventione I 3I, 5I). M. F. Quintilianus, Ausbildung des Redners, hrsg. und übers. v. H. Rahn, Bd. I, Darmstadt 1972, 596 (V II, 2); Melanchthon, Compendiaria dialectices ratio (I52I), in: Melanchthon CR, Bd. 20, Sp. 73Iff. und Erotemata dialectices, in: Melanchthon CR, Bd. 13, Sp. $593 \mathrm{ff}$;; allgemein und aus heutiger Perspektive zusammenfassend: Ueding/Steinbrink (Anm. I), $245 \mathrm{ff}$.

${ }^{69}$ Hans Schäufelein, Schmerzensmann über dem Almosenkasten, Nördlingen, Stadtmuseum; vgl. Ausst. Nürnberg 1983 (Anm. 15), 424. 


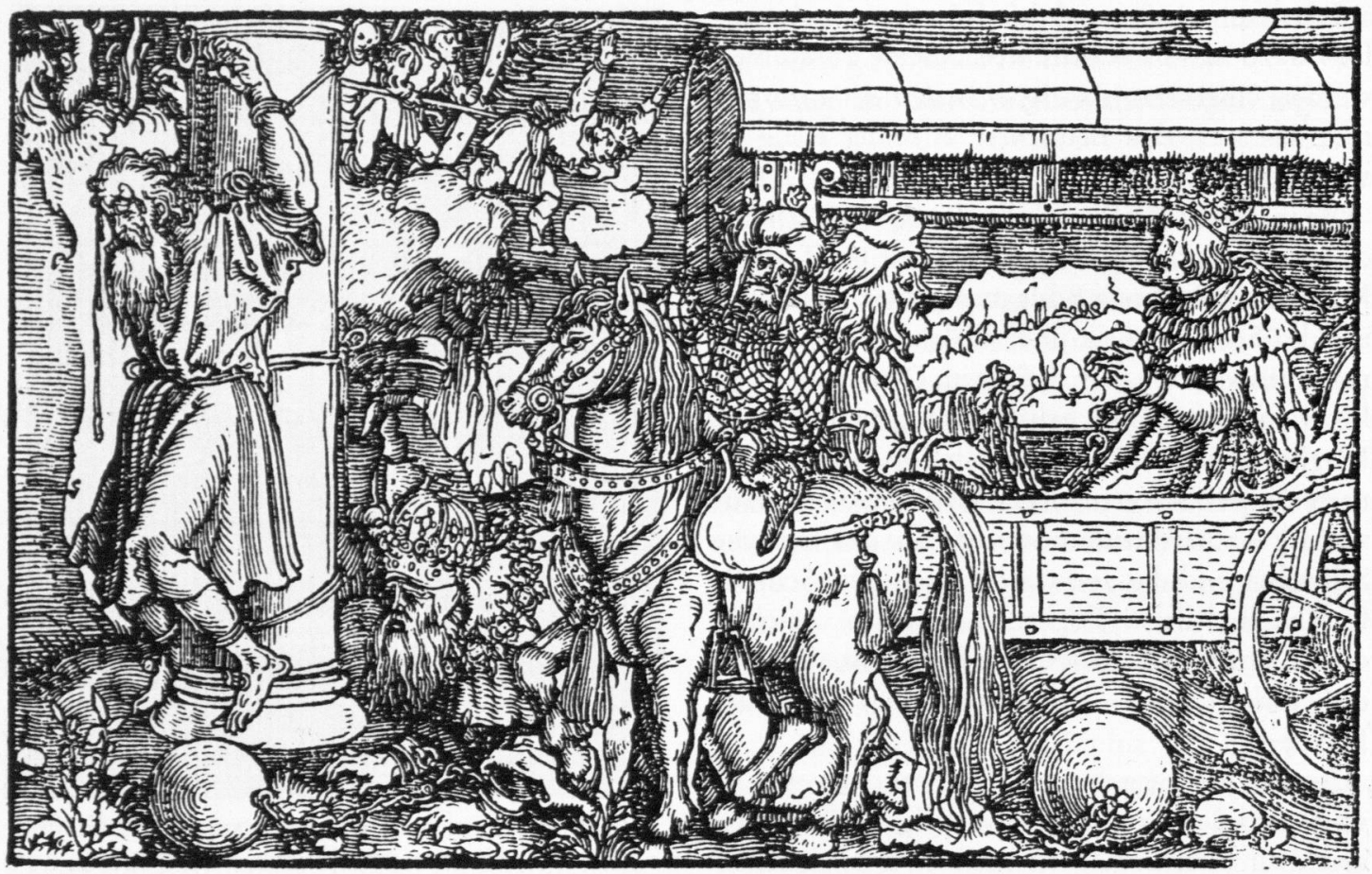

8. Petrarca-Meister, Von der Freyheit, Holzschnitt zu: F. Petrarca, Von der Artzney bayder Glück, Augsburg, 1532, fol. XIII ${ }^{\mathrm{v}}$

ordnung gab, mit der das Problem geregelt werden sollte ${ }^{70}$. In der Georgskirche wurde ein "Armenkasten« aufgestellt und das Bild Schäufeleins darüber sollte die Gemeinde zu Almosen auffordern. Christus erscheint in Schäufeleins Bild als Schmerzensmann über dem Almosenkasten. Ein leuchtendes Wolkenband trennt ihn von dem Bildraum, einem Kirchenraum, in dem sich eine Vielzahl von Gestalten aufhalten, Reiche, die den am Boden sitzenden Armen Geld und Nahrung bringen, und andere, die ihr Almosen in den Armenkasten werfen. Deutlicher als hier geschehen kann die Motivkollision, die aus der Durchdringung zweier Darstellungsebenen resultierende Diskontinuität, nicht sichtbar gemacht werden. Diese Diskonti-

${ }^{70} \mathrm{H}$. Ch. Rublach, Nördlingen zwischen Kaiser und Reformation, in: Archiv für Reformationsgeschichte, Bd. 71,1980, II $8 f$.

${ }^{71}$ Melanchthon gibt in den 'Erotemata dialectices< folgende Definition: "Enthymema est imperfectus Syllo- nuität würde verschleiert, wenn wir hier wieder von einem Simultanbild sprechen würden. Es ist ein Bild mit argumentativer Struktur der Darstellung. Der Betrachter wird geradezu genötigt, den Zusammenhang zwischen beiden Ebenen herzustellen, indem er sie in einem Schluß aufeinander bezieht. Diesen Schluß kann man als ein Enthymen bezeichnen, wenn man, wie es in der lateinischen Rhetoriktradition üblich war, diese Schlußfigur als verkürzten Syllogismus auffaßt, als einen Syllogismus, der nur noch eine Proposition und die Konklusion enthält ${ }^{71}$. Er könnte so lauten: Christus hat uns Menschen gegenüber Barmherzigkeit bewiesen (das zeigt die Darstellung des Schmerzensmannes), also müssen auch wir unse-

gismus, quia fit recitata una syllogismi propositione, et addita conclusione. Omittitur altera propositio, vel brevitatis causa, quia cum nota sit, videtur recitatio ingrata esse, vel quia non satis firma est « (Melanchthon CR, Bd. 13, Sp. 617). 


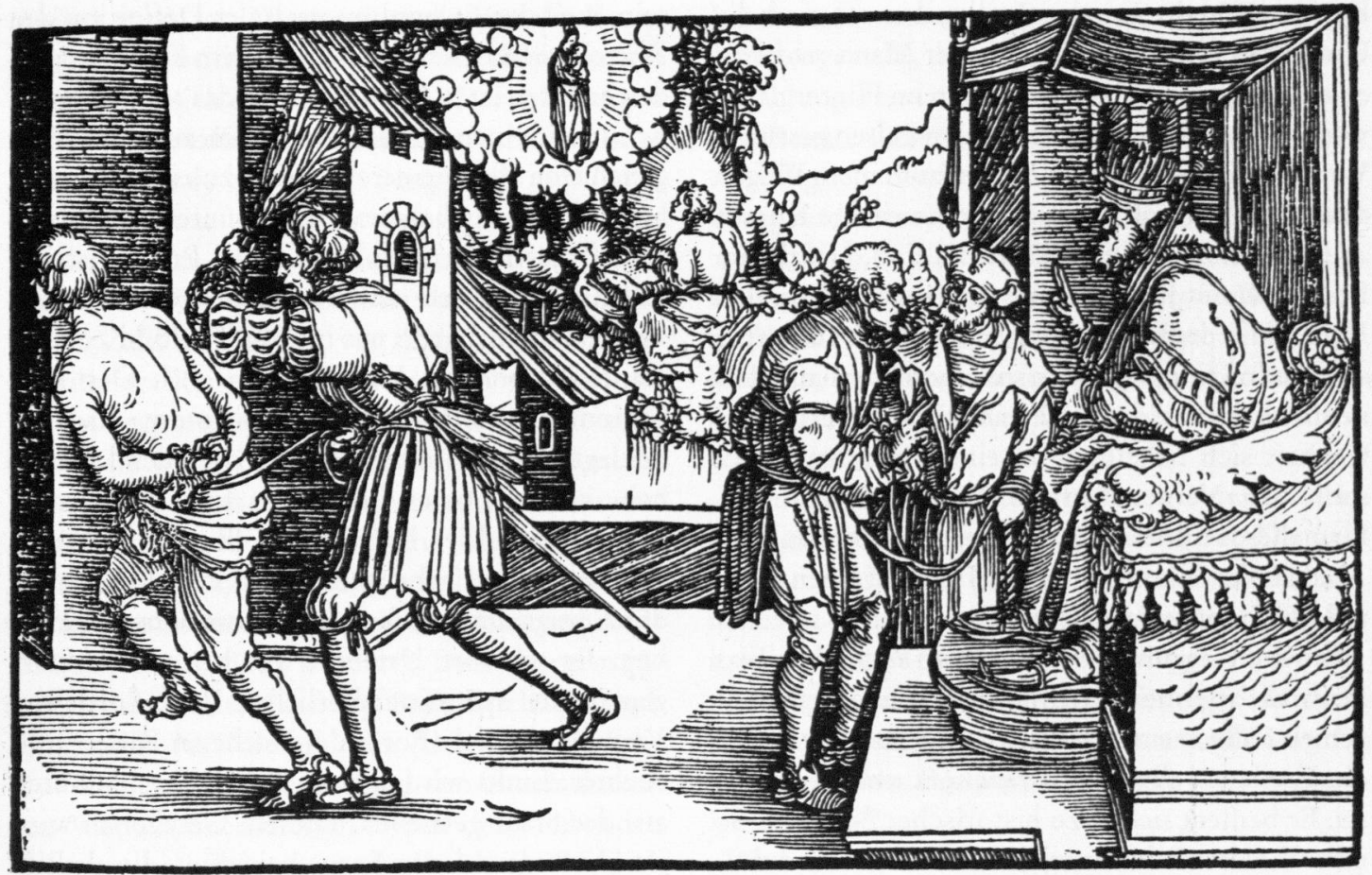

9. Petrarca-Meister, Von dem Ellend, Holzschnitt zu: F. Petrarca, Von der Artzney bayder Glück, Augsburg, 1532, fol. LXXIX ${ }^{\mathrm{r}}$

ren Mitmenschen gegenüber Barmherzigkeit beweisen (das zeigt die Darstellung in den beiden Ecken). Der Mittelsatz, daß wir dem Beispiel Christi nachfolgen müssen und seine Aufforderung zur Nächstenliebe für den Christen Gesetz ist, wird als allgemein gültig vorausgesetzt und bleibt unausgesprochen. Allerdings kann die zweiteilige Bildstruktur auch anders gelesen werden, nämlich als konditionales Argument, das das Erbarmen Christi für den Betrachter nicht voraussetzt, sondern verheißt. Die Bildinschrift bietet diese Verständnismöglichkeit sogar an: »Gebent Ewr heilig almusen den armen So wierd sich Got vber ewr Sund erbarmen ${ }^{72}$. Theologisch ist dies natürlich ein Rückfall in die Vorstellungen von der

\footnotetext{
${ }^{72}$ Zitiert nach: Ausst. Nürnberg 1983 (Anm. 15), 424.

${ }^{73}$ F. Petrarca, Von der Artzney bayder Glück/ des guten vnd widerwertigen. Unnd weß sich ain yeder inn $\mathrm{Ge}$ lück vnd vnglück halten sol. Auß dem lateinischen in das Teutsch gezogen. Mit künstlichen fyguren durch-
}

Werkgerechtigkeit, die von den Reformatoren schwerlich gebilligt worden wäre, aber für die Übergangszeit, in der man sich von den eingewurzelten Denkgewohnheiten erst lösen mußte, doch wohl symptomatisch ist.

Eine wahre Fundgrube für Beispiele der Bildargumentation sind die Illustrationen des Petrarcameisters zur deutschen Ausgabe von Petrarcas $>$ De remediis utriusque fortunae<, die 1532 erschien ${ }^{73}$. Die Illustrationen, nach den Angaben Sebastian Brants von einem bisher nicht identifizierten Künstler geschaffen, sind ein vom Text ausgehender, aber sehr oft ganz frei erfundener bildlicher Kommentar zu den Aussagen der »Vernunft « in den Dialogen Petrarcas. Das Bild, das über dem auß/ gantz lustig und schoen gezyeret, Augsburg 1532; vgl. W. Scheidig, Die Holzschnitte des Petrarcameisters, Berlin 1955. Die alte Frage, ob der Petrarca-Meister mit Hans Weiditz zu identifizieren sei oder nicht, darf hier ausgeklammert bleiben. 
Kapitel >Von der Freyheit< steht, demonstriert die Unfreiheit (Abb. 8) ${ }^{74}$. Ein greiser Mann stirbt an eine Säule gefesselt. Rechts davon im Hintergrund wird ein jüngerer Mann von einem Felsen gestürzt. Vorne wird ein König in Ketten auf einem Wagen davon geführt und ein Kaiser, dem riesige Kugeln an Füße und Hände geschmiedet sind, kriecht am Boden. Wenn Jung und Alt und sogar König und Kaiser, die doch eigentlich niemandem untertan sind, unfrei sind, werkann sich dann überhaupt frei nennen und was ist die Freiheit dann wert: »ewr freyheit sich behellfent an einem dünnen faden stellt die $»$ Vernunft« fest. Die Argumentationsform dieses Bildes ist die inductio, bei der aus einer Aneinanderreihung einzelner Fälle auf einen generell gültigen Satz geschlossen wird75.

Das Bild argumentiert so, wie auch der Text Petrarcas argumentiert, denn auch dieser reiht einzelnen Fälle aneinander, aus denen er ableitet, daß die Freiheit »allweg schwanckent vnd hinfällig« sei. Er bedient sich dazu historischer Beispiele. So ist auch unser Bild streng genommen eine Induktion, die in drei der vier gezeigten Fälle historische Exempla anführt. Der König rechts ist Jugurta, der nach seiner Niederlage von Marius im Triumph vorgeführt und dann hingerichtet wurde. Der Kaiser ist mit Valerianus zu identifizieren, der im Kriege den Persern in die Hände fiel und in Gefangenschaft starb. Der an die Säule gebundene Mann ist wohl mit dem römischen Feldherrn Atilus Regulus zu identifizieren, der von den Karthagern gefangen und grausam ermordet wurde.

Die Kennzeichnung der Argumentationsform als Induktion wird gleichwohl aufrechtzuhalten

${ }^{74}$ Scheidig (Anm. 72), 58.

$75 \gg$ Inductio est ex sigularibus sufficientibus enumeratis constituere universalem* (Erotemata dialectices 1547 : Melanchthon CR, Bd. 13, Sp. 620).

${ }^{76} \leadsto$ Exemplum est forma argumenti, qua singulare per aliud singulare in una specie confirmamus, propter similem rationem* (Erotemata dialectices 1547: Melanchthon CR, Bd. 13, Sp. 621). Vgl. Quintilian (Anm. 67), $596 \mathrm{ff}$. (V, II, Iff.).

77 Scheidig (Anm. 72), 265.

${ }^{8}$ Eine Einführung (mit weiterführender Literatur) bietet: Illustrierte Flugblätter des Barock. Eine Auswahl, hrsg. von W. Harms, J. R. Paas u.a. (Deutsche Neudrucke, Reihe Barock Bd. 30), Tübingen 1983. sein, weil das Exemplum nach der Definition der Rhetoriker das Schließen von einem Einzelfall auf den anderen ist $^{76}$. Natürlich gibt das tertium comparationis einen Ansatzpunkt, um aus dem Vergleich eine allgemeinere Regel abzuleiten, deshalb hat Cicero ja auch das exemplum unter dem Oberbegriff der inductio subsummiert. Primär ist das Exemplum jedoch eine zweigliedrige Form. Ein Beispiel dafür haben wir in dem Titelbild zu dem Kapitel >Von dem Ellend، (Abb. 9) 77 . Der Text beginnt damit, daß sich der "Schmerz" darüber beklagt, daß er »mit vnrecht in das ellend getrieben« werde. Dieses Geschehen wird im Vordergrund des Bildes beschrieben. Rechts steht ein gefesselter und gebeugter Mann vor dem Thron des Königs und hat die Hände zum Schwur erhoben. Er schwört Urfehde, das heißt, er erklärt gemäß der spätmittelalterlichen Prozeßordnung Verzicht auf jede Form der Rache an Kläger und Richter. Links wird er dann halbnackt mit Ruten aus der Stadt getrieben. Diesem Geschehen wird im Hintergrund eine Szene beigefügt, die als Bild im Bild erscheint und jedem zeitgenössischen Betrachter wohl unmittelbar vertraut war: die Darstellung des Evangelisten Johannes auf Patmos. Seine Verbannung ist das tröstliche Exempel dafür, daß das Elend der Verbannung auch positive Folgen haben kann. Mit dieser Wendung entspricht die Illustration dem Text, in welchem die Vernunft den Klagen des Schmerzens mit verschiedenen antiken Beispielen widerspricht. Die Bildargumentation ist wieder so angelegt, daß der Betrachter den eklatanten Sprung zwischen den beiden Szenen oder Ebenen wahrnimmt und sti-

79 Unter anderem die Illustration der Visionen des Propheten Zacharias: J. Walter, Herrade de Landsberg, Hortus Deliciarum. Recueil de cinquant planches... avec texte d'introduction historique, littéraire et archeologique, Straßburg 1952, fol. 64v und 65r, 75.

${ }^{80}$ R. L. Füglister, Das Lebende Kreuz. Ikonographischikonologische Untersuchungen der Herkunft und Entwicklung einer spätmittelalterlichen Bildidee und ihrer Verwurzelung im Wort, Diss. Fribourg, Einsiedeln 1964.

${ }^{81}$ Ambrogio Lorenzetti, Allegorie der Erlösung, 57,5 x II $8,5 \mathrm{~cm}$, Siena, Pinacoteca; vgl. P. Torriti, La Pinacoteca Nazionale di Siena. I dipinti dal XII al XV secolo, Genua 1977, 1r6f. 
muliert wird, sein Wissen über die Vita des Evangelisten als positive Assoziation einzubringen, mit deren Hilfe sich die Bildteile zu einer schlüssigen Bildaussage verknüpfen lassen.

Ich möchte es bei diesen Beispielen, mit denen die klassischen Argumentationstypen illustriert werden sollten, belassen. Es wäre ein Leichtes aus der Zeit der Reformation noch weitere Exempel in großer Zahl anzuführen, vor allem wenn die Flugblattillustration einbezogen werden würde ${ }^{78}$. So beliebt argumentative Bilder in dieser Zeit auch waren: sie waren damals selbstverständlich nichts Neues. Ihre Vorläufer haben sie zum einen in der didaktischen und »erbaulichen « Illustration des Mittelalters. Einzelne Bilder aus dem bortus deliciarum der Herrad von Landsberg könnten dafür als Beispiel angeführt werden 79 . Diese Form argumentativer Bilder fand im Spätmittelalter auch Eingang in das Tafelbild, die Altarkunst und die Wandmalerei. Hier könnte auf den in verschiedenen Werken überlieferten Typus des "Lebenden Kreuzes $\ll$ hingewiesen werden ${ }^{80}$. Als ein Beispiel, das gerade im Hinblick auf die hier so ausführlich besprochenen Werkgruppe Cranachs von größtem Interesse ist, soll die >Allegorie der Erlösung erwähnt werden, ein um I340 zu datierendes Sieneser Tafelbild, das Ambrogio Lorenzetti zugeschrieben wird ${ }^{81}$. Das Bild legt dar, daß der Tod mit der Vertreibung aus dem Paradies in die Welt gekommen ist, in der er, wie die große Zahl der Leichen im Zentrum des Bildes vor Augen führt, grausam herrscht. Durch den Tod Christi jedoch wird er überwunden und das Ziel der Feilsgeschichte ist, wie die rechte Bildhälfte zeigt die Auferweckung der Erwählten zum ewigen Leben im Augenblick des Gerichts. In einer einheitlichen

${ }^{82}$ R. Colella, Die Erlösungsallegorie des Ambrogio Lorenzetti, in: Belting/Blume (Anm. 4), I7fff.; hier I80 (der Aufsatz ist die Kurzfassung einer Münchner Magisterarbeit gleichen Titels). Die Verf. kommt von ihrer Interpretation des Lorenzetti-Bildes aus zu Feststellungen, die jenen nahezu entsprechen, die oben bei der Behandlung von Cranachs >Gesetz und Evangelium getroffen wurden. Es fehlt nur die Folgerung, daß die *aus der Kompilation und Montage disparater Bildelemente resultierende komposite Struktur* (I82) eine spezifisch argumentative Struktur ist. Daß dieser Schluß nicht gezogen wurde, mag daran liegen, daß die Begrif-
Landschaft werden die Ereignisse und Motive zusammengestellt, die nicht als zusammenhängende Erzählung verstanden werden können, sondern, wie Renate Colella schrieb, die diesem Bild eine eindringliche Studie gewidmet hat, »als Teile eines übergeordneten Arguments $\ll^{82}$. Es ist unübersehbar, daß wir in dieser Tafel Lorenzettis einen mittelalterlichen Vorläufer für die Bilderfindung Cranachs haben. Leider ist es im Augenblick nicht möglich, die Zusammenhänge genauer zu bestimmen, weil uns die Kenntnis notwendiger Zwischenglieder fehlt.

Von der Sieneser Tafel werden wir unmittelbar auf den anderen Zweig argumentativer Darstellung verwiesen, der hier als Vorläufer anzuführen ist. Es ist die monumentale Allegorie, wie sie in der italienischen Trecentokunst entwickelt wurde. Ambrogio Lorenzettis Fresken in der Sala della Pace des Palazzo Pubblico in Siena sind dafür ein wohlbekanntes Beispiel, an das nur kurz erinnert werden soll ${ }^{83}$.

Diese beiden Zweige stehen für unterschiedliche Geltungs- und Wirkungsbereiche. Im ersten Fall ist es die private religiöse Andacht und Unterweisung, in der Wissen vermittelt oder durch Memorieren gefestigt wird. Im zweiten Fall ist es das politische Programm, das durch die Bilder vor der Kommune öffentlich und dauerhaft festgeschrieben werden soll.

Trotz dieser Vorläufer darf man sagen, daß das Zeitalter der Reformation für das argumentative Bild eine besondere Blütezeit brachte. Die argumentative Rede setzt, so lehrt die Rhetorik, beim Zuhörer Unkenntnis oder Dissens voraus und ihr Ziel ist es, mit rationalen Mitteln zu überzeugen ${ }^{84}$. $\mathrm{Da}$ zugleich sprachliche und emotional wirksa-

fe Argumentation/Argument ohne begriffsgeschichtliche Reflexion benutzt wurden. Die Verf. benutzt überwiegend das Wort $\gg$ Argument und meint damit den gedanklichen Gehalt oder die Aussage eines Werkes. Auf die in der Tradition der Dialektik verankerte Form der argumentatio geht sie nicht ein.

${ }^{8} \mathrm{Zu}$ diesem Komplex vgl. die Beiträge von $\mathrm{H}$. Belting, $\mathrm{B}$. Kempers und Q. Skinner in: H. Belting und D. Blume, Hrsg. a.a.O. (Anm. 4).

${ }^{84} \mathrm{E}$. Eggs, Argumentation, in: Historisches Wörterbuch der Rhetorik (Anm. I), Sp. 9I4. 
me Mittel eingesetzt werden, um zu erfreuen und zu bewegen, um so das Hauptziel des Überzeugens zu erreichen, sei nur am Rande erwähnt. Natürlich war in der Reformation diese Ausgangssituation von Unkenntnis und Dissens in besonderem Maße gegeben. Der Religionsstreit forderte zur Argumentation heraus, und die Bilder wurden in diesen Streit eingespannt. Den Intentionen der Reformatoren kam auch ein anderes entgegen: das argumentative Bild fordert in ganz anderem Maße als das Repräsentations- oder Erzählbild die Eigenleistung, das Mitdenken des Rezipienten, der ja erst dadurch, daß er den durch das Bild präsupponierten Schluß zieht, die Bildintention zu ihrem Ziele kommen läßt. Diese Einbeziehung des Betrachters korrespondiert mit der Eigenständigkeit, die die Reformatoren den Gläubigen hinsichtlich der Aufnahme der biblischen Botschaft zubilligten.

- Daß das aus diesen Quellen herzuleitende argumentative Bild auch zum monumentalen Altarbild aufgewertet wurde, wie wir es im Weimarer Altar gesehen haben, ist völlig konsequent. Das argumentative Bild bedingte die Dominanz der rationalen Rezeption, die mit der Dominanz des
Wortes in der protestantischen Theologie korrespondierte. Anders als das narrative und das repräsentative Bild, die bis dahin in der Funktion von Altar- und Andachtsbildern vorherrschten, versperrte sich das argumentative Bild der Adoration, dem Bilderkult, weil es aufgrund der Diskontinuitäten und Brüche in seiner Darstellung die Illusion von Wirklichkeit verhinderte, so daß eine Verwechslung der Existenz des Bildes mit der Existenz des im Bild Dargestellten unmöglich war, und es war zur gläubigen Adoration nicht tauglich, weil es die Sinnkonstituion ausdrücklich dem Rezipienten zuwies, der, indem er die ihm durch die Darstellung suggerierten Schlußfolgerungen zog, wieder auf Wort und Geist verwiesen wurde. Schließlich konnte ein solcher Altar als monumentales, an die Öffentlichkeit adressiertes Werk zur Fixierung des Bekenntnisses beitragen, was gerade in einer Zeit erwünscht sein mußte, in der es erhebliche Bekenntniskonflikte innerhalb des Protestantismus gab, mit den Folgen einer Verunsicherung der Glaubensgenossen. Nicht zuletzt seines affirmierenden Charakters wegen durchlief das argumentative Bild eine Karriere, die sich bis in die Gegenwart verfolgen läßt.

Abbildungsnachweis: I Photo Museum. -2 Photo Constantin Beyer, Weimar. -3 Photo Museum. $-4,6$ Reproduktion aus W. Hofmann, Luther und die Folgen für die Kunst, Katalog der Ausstellung Hamburg 1983.5. Photo Museum. -7 Photo: Photo Hirsch Nördlingen. $-8,9$ Reproduktionen aus F. Petrarca, Von der Artzney...Augsburg I532. 